\title{
Characterization of Natural and Induced Variation in the LOV1 Gene, a CC-NB-LRR Gene Conferring Victorin Sensitivity and Disease Susceptibility in Arabidopsis
}

\author{
Teresa A. Sweat, ${ }^{1}$ Jennifer M. Lorang, ${ }^{1}$ Erica G. Bakker, ${ }^{2}$ and Thomas J. Wolpert ${ }^{1}$ \\ ${ }^{1}$ Department of Botany and Plant Pathology, Oregon State University, Corvallis, OR 97331-2902, U.S.A.; ${ }^{2}$ Department \\ of Horticulture, Oregon State University, Corvallis, OR 97331-7304, U.S.A.
}

Received 8 August 2007. Accepted 26 September 2007.

\begin{abstract}
The fungus Cochliobolus victoriae, the causal agent of Victoria blight, produces a compound called victorin that is required for pathogenicity of the fungus. Victorin alone reproduces disease symptoms on sensitive plants. Victorin sensitivity and susceptibility to $C$. victoriae were originally described on oats but have since been identified on Arabidopsis thaliana. Victorin sensitivity and disease susceptibility in Arabidopsis are conferred by LOV1, a coiled-coilnucleotide-binding-leucine-rich repeat (CC-NB-LRR) protein. We sequenced the LOV1 gene from 59 victorin-insensitive mutants and found that the spectrum of mutations causing LOV1 loss of function was similar to that found to cause loss of function of RPM1, a CC-NB-LRR resistance protein. Also, many of the mutated residues in LOV1 are in conserved motifs required for resistance protein function. These data indicate that LOV1 may have a mechanism of action similar to resistance proteins. Victorin sensitivity was found to be the prevalent phenotype in a survey of $\mathbf{3 0}$ Arabidopsis ecotypes, and we found very little genetic variation among LOV1 alleles. As selection would not be expected to preserve a functional $L O V 1$ gene to confer victorin sensitivity and disease susceptibility, we propose that LOVI may function as a resistance gene to a naturally-occurring pathogen of Arabidopsis.
\end{abstract}

Corresponding author: Thomas J. Wolpert;

E-mail: wolpertt@science.oregonstate.edu

Nucleotide sequence data for LOVI alleles from the following Arabidopsis thaliana ecotypes and related species are available in the GenBank database under accession numbers Cl-0, EF472599; Ler-0, EU053655; Sp0, EU053656; Sha, EU053657; Tol-0, EU053658; C24, EU053659; Rubezhnoe-2, EU053660; Bay-0, EU053661; Cvi-0, EU053662; En-1, EU053663; Kas-1, EU053664; Nd-0, EU053665; No-0 (victorin-sensitive individual), EU053666; Ws-0, EU053667; Ws-2, EU053668; Mt-0, EU053669; Bil-5, EU053670; HR-10, EU053671; Fei-0, EU053672; An-1, EU053673; Ts-1, EU053674; Yo-0, EU053675; Se-0, EU053676; Bur-0, EU053677; Ag-0, EU053678; Vind-1, EU053679; RRS-10, EU053680; Lov-1, EU053681; KZ-1, EU053682; Col-4, EU053686; No-0 (victorininsensitive individual), EU053687; Arabidopsis korshinskyi, EU053683; Olimarabidopsis pumila, EU053684; and Arabidopsis suecica, EU053685.

The Spotlight logo represents articles that, in the opinion of the senior editor and editor-in-chief, are of special interest to a broad readership.

* The $e$-Xtra logo stands for "electronic extra" and indicates that two supplemental tables are available online.
The Arabidopsis thaliana genome encodes 149 nucleotidebinding-leucine-rich repeat (NB-LRR) proteins, including 83 with an $\mathrm{N}$-terminal toll/interleukin-1 receptor (TIR) domain and 51 with an N-terminal coiled-coil (CC) domain (Meyers et al. 2003). Nearly all plant NB-LRR proteins that have been characterized to date function as disease-resistance proteins. These proteins directly or indirectly recognize pathogen effectors known as avirulence proteins (Jones and Dangl 2006). Recognition triggers a resistance response in the host, typically including a programmed cell death (PCD) response known as the hypersensitive response (HR) at the site of pathogen contact (Greenberg and Yao 2004; Heath 2000). The LOCUS ORCHESTRATING VICTORIN EFFECTS1 (LOVI) gene is unusual in that it is a CC-NB-LRR protein found to confer susceptibility to infection by the fungus Cochliobolus victoriae in Arabidopsis (Lorang et al. 2007). C. victoriae was originally described as the causal agent of Victoria blight of oats (Avena sativa) (Meehan and Murphy 1946). Pathogenic strains of $C$. victoriae produce a group of cyclized pentapeptides called victorin (Macko et al. 1985; Wolpert et al. 1985), and treatment with victorin alone reproduces disease symptoms on sensitive plants (Lorang et al. 2004; Meehan and Murphy 1947). For both oats and Arabidopsis, only genotypes that are sensitive to victorin are susceptible to infection by $C$. victoriae (Lorang et al. 2004; Sweat and Wolpert 2007; Walton 1996; Wolpert et al. 2002). Victorin triggers a PCD response in sensitive plants (Coffeen and Wolpert 2004; Curtis and Wolpert 2002, 2004; Navarre and Wolpert 1999; Yao et al. 2001, 2002) and also induces host defense responses (Lorang et al. 2007; Mayama et al. 1986; Shain and Wheeler 1975; Ullrich and Novacky 1991; Wheeler and Black 1962). In oats, the gene that confers sensitivity to victorin and susceptibility to $C$. victoriae is the $V b$ gene. The $V b$ gene is believed to share identity with the $P c$ 2 gene, which confers resistance to crown rust of oats caused by the fungus Puccinia coronata (Litzenberger 1949), as extensive genetic and mutagenic studies have failed to separate crown rust resistance from Victoria blight susceptibility (Luke et al. 1966; Mayama et al. 1995; Rines and Luke 1985; Welsh et al. 1954). The genetic connection between $V b$ and $P c-2$ and the fact that victorin induces a host response similar to that mediated by resistance genes, including both induction of defense responses and PCD, strongly suggest that susceptibility to $C$. victoriae in oats is conferred by a resistance gene. The recent cloning of $L O V I$ has shown that a protein of the NBLRR class is indeed responsible for conferring both sensitivity to victorin and susceptibility to $C$. victoriae in Arabidopsis 
(Lorang et al. 2007). Interestingly, recent work strongly suggests that the $P c$ gene, which confers susceptibility to milo disease in sorghum (Sorghum bicolor) caused by the fungus Periconia circinata, is also an NB-LRR gene (Nagy et al. 2007). Similar to the situation for $C$. victoriae, $P$. circinata produces phytotoxic peptides, called PC-toxin (Macko et al. 1992), that alone reproduce disease symptoms (Wolpert and Dunkle 1983), and both sensitivity to PC-toxin and susceptibility to the fungus are conferred by the $P c$ gene.

We previously reported isolation and genetic characterization of 63 independent ethyl methanesulfonate (EMS)-generated mutants that had completely lost sensitivity to victorin from a screen of approximately 212,000 seedlings (Sweat and Wolpert 2007). These mutants fell into two complementation groups, consisting of 59 lov 1 mutants and four carrying mutations in the LIVI gene, which was found to encode thioredoxin $h 5$ (ATTRX5). We showed that loss of victorin sensitivity resulted in complete loss of susceptibility to $C$. victoriae in both a lovl and a livl mutant (Sweat and Wolpert 2007), as was expected, given that there is a strict correlation between sensitivity to victorin and susceptibility to $C$. victoriae in both oats and Arabidopsis (Lorang et al. 2004; Walton 1996; Wolpert et al. 2002). In the present study, we used a twofold approach to better understand the function of LOV1 in conferring victorin sensitivity. First, we sequenced the LOVI gene from each of the 59 lovl mutants. This revealed that many of the mutations leading to loss of function of LOV1 are in regions that are conserved among NB-LRR proteins and are known to be required for resistance protein function. Our screen was similar in scope to another large-scale mutagenesis screen conducted on RPMI (Tornero et al. 2002), a CC-NB-LRR gene that confers resistance to Pseudomonas syringae carrying avrRpml or avrB (Bisgrove et al. 1994; Grant et al. 1995). By comparing the mutations leading to LOV1 loss of function with those identified in the RPM1 mutant screen, we found that a similar spectrum of mutations causes loss of function of these proteins, suggesting that LOV1 may function in a manner analogous to a known resistance protein. Second, in order to survey the prevalence of victorin sensitivity in Arabidopsis and the naturally-occurring variation in LOVI alleles, we sequenced the LOV1 gene from 30 Arabidopsis ecotypes and correlated these data with the response of each ecotype to victorin treatment. This analysis showed that sensitivity to victorin is much more common than insensitivity and that there is very little genetic variation among LOVI alleles. Because a functional LOVI gene is not likely to be either selected for or maintained as a means to confer victorin sensitivity and susceptibility to $C$. victoriae, we propose that $L O V 1$ may be acting as a resistance gene to a naturally occurring pathogen of Arabidopsis.

\section{RESULTS}

\section{Loss-of-function lov1 alleles.}

The LOVI coding region from each of the 59 previously isolated lovl mutants that had completely lost sensitivity to victorin was amplified by polymerase chain reaction (PCR) and was sequenced. Each allele was found to carry a single point mutation in the LOVI gene, with the exception of alleles lov11 and lov $1-44$, which each contain two point mutations (Supplementary Table S1). All mutations were G to A (or C to T) transition mutations, as is expected with EMS mutagenesis. Five alleles had mutations that result in creation of a premature stop codon. Two alleles, lov1-1 and lov1-51, contain mutations at the junction between the first intron and second exon. Allele lov1-51 has a $\mathrm{G}$ to A mutation in the last nucleotide of intron 1 , while lov1-1 has a mutation of the first $\mathrm{G}$ of exon 2. As these positions are highly conserved at splice junctions, both mutations likely interfere with correct splicing of exons 1 and 2. Therefore, the second mutation in lov $1-1$, which is in exon 3 , was not included in further analysis because its effect on LOV1 function could not be independently evaluated. The remaining 51 alleles each contain a single amino-acid change (missense mutation) resulting in complete loss of LOV1 function. Some of these alleles were found to be identical, leaving 44 unique alleles affecting 42 amino-acid residues. Most of these mutants were wild-type in appearance, although a few had unusual morphologies or poor seed set, likely resulting from unrelated second-site mutations.

\section{Characterization of mutants with reduced sensitivity to victorin.}

In our mutant screen, we also isolated 10 mutants with reduced sensitivity to victorin. These mutants were selfed and tested through at least three generations to ensure that the phenotype was consistent and not due to heterozygosity of a mutation that would otherwise cause complete loss of function. The reduced-sensitivity mutants show no or only slight symptoms after infiltration of leaves with victorin. All show some symptoms by 2 to 3 days in the more sensitive detached leaf assay, in which a leaf is removed and placed in $250 \mu \mathrm{l}$ of a $10 \mu \mathrm{g} / \mathrm{ml}$ solution of victorin for 3 days, but symptom development is delayed in comparison with that in wild-type plants. Some mutants show only yellowing after treatment with victorin for 3 days (e.g., lov1-61), while others show tissue collapse that develops more slowly than in wild-type plants. These mutants were not genetically characterized because it is difficult to distinguish reduced victorin sensitivity due to mutation versus reduced sensitivity due to heterozygosity of wild-type $L O V I$ in segregation analyses. However, we sequenced the LOVI gene from each of these mutants and found a single point mutation in five of the ten alleles. We cannot decisively say that these mutations are the cause of the reduced sensitivity. However, because the vast majority of loss-of-function mutations uncovered in our mutant screen were in the LOVI gene, this is a reasonable assumption. The only other gene that was identified in our mutant screen as being required for the response to victorin was ATTRX5 (Sweat and Wolpert 2007). This gene was also sequenced from each of the reduced-sensitivity mutants, but no mutations were found. Therefore, the mutations in these five lov1 alleles were considered to cause partial loss of LOV1 function in further analysis. Interestingly, one of the alleles, lov1-60, has an R594Q mutation, which is the same as one of the mutations in allele lov1-44. Because lov1-44 is a completely nonfunctional allele, the other mutation in this allele, D47N, must have at least a partial effect on LOV1 function. Therefore, D47N was considered as another partial loss-offunction mutation in further analysis, although it is possible that this mutation alone causes complete loss of function. Another reduced-sensitivity allele, lov1-64, carries the mutation A547T. Interestingly, in lov1-22, the mutation A547V results in complete loss of function. The five mutants with reduced sensitivity that did not contain a mutation in LOV1 (or ATTRX5) may contain mutations in other genes affecting victorin sensitivity, or they may have mutations in regulatory regions of LOV1 or ATTRX5, such as the promoters, which were not sequenced in this study. Two of these five mutants also had unusual leaf morphologies, which may cause an apparent decrease in victorin sensitivity due to reduced uptake of victorin or other nonspecific effects.

\section{Comparison of lov1 versus rpm1 mutant alleles.}

Although the LOV1 gene confers victorin sensitivity and susceptibility to C. victoriae (Lorang et al. 2004), it belongs to the CC-NB-LRR class of genes (Lorang et al. 2007), which 
are typically associated with resistance. An extensive mutagenesis study has been performed on the RPM1 resistance gene (Tornero et al. 2002), which is also a CC-NB-LRR gene. Therefore we compared the spectrum of mutations uncovered in their work and in another study of RPMI (Grant et al. 1995) with the results of our study. We reasoned that if LOV1 is functioning in a manner analogous to a resistance protein, the loss-of-function alleles uncovered for $L O V 1$ should show similarities to the mutant alleles found to cause loss of RPM1 function. The RPM1 studies uncovered 61 alleles with a single $\mathrm{G}$ to A or $\mathrm{C}$ to $\mathrm{T}$ mutation that resulted in complete loss of RPM1dependent HR. The other mutations turned up in these studies were not of the type expected to be found in an EMS mutagenesis screen and were therefore not included in comparisons of lovl versus rpml loss-of-function alleles. Of the $61 \mathrm{rpm} 1$ alleles, 10 (eight unique alleles) had mutations resulting in premature stop codons. The remaining 51 alleles all contained single missense mutations. These represent 43 unique nucleotide changes affecting 39 amino-acid residues. Tornero and associates (2002) also found a single point mutation in each of four partial loss-of-function rpml alleles. Therefore, the number and type of mutant alleles found for RPM1 versus LOVI are very similar, allowing a direct comparison of the mutations leading to loss of function in these two genes.

In order to compare the overall distribution of missense mutations resulting in loss of function of LOV1 versus RPM1, we plotted the number of loss-of-function alleles containing single amino-acid substitutions in each 50-amino acid window across LOV1 (Fig. 1A). For comparison, we performed an identical analysis for RPM1 (Fig. 1B), similar to that performed by Tornero and associates (2002). To preserve as much information as possible and to prevent skewing the data due to the isolation of multiple identical alleles, we counted the mutant alleles in three different ways: the total number of alleles, the number of unique alleles, and the number of amino acids affected by mutation in each window. These last two counts were only different in the few cases in which two different nucleotide changes affected the same amino acid. In most cases, all three counts gave very similar numbers. However, there were notable exceptions, particularly the first window (1 to 50) for LOV1 and window 351 to 400 for RPM1. These each contained multiple mutations of a glycine codon (Gly 9 for LOV1 and Gly 384 for RPM1). EMS mutagenesis is known to exhibit site preferences, based primarily on the nucleotides at the -2 to +2 positions flanking the mutated $\mathrm{G}$, possibly due to differing efficiencies of the mismatch repair system at these sites (Greene et al. 2003). For example, the nucleotide change in LOVI that results in the mutation of Gly 9 is in a particularly favorable context for EMS mutagenesis, as all nucleotides in the -2 to +2 positions are overrepresented in EMS-mutagenized populations. Therefore, the affected guanine is expected to be mutated 2.7 times more often than an "average" G. In order to minimize the effects of EMS biases, we focused further analysis on the number of unique alleles.

The overall distribution of mutations in the lov 1 and rpml alleles are only somewhat similar. Both show a preponderance of mutations in the central portion of the protein, with mostly low numbers of mutations at either end of the gene (Fig. 1). Additionally, both have a peak of mutations in window 751 to 800 , surrounded by windows with low numbers of mutant alleles. However, there are notable differences, such as the peak of mutations in the first window of LOV1, which includes the $\mathrm{CC}$ domain of this protein. There is also a skew in the area containing the most mutations. Both show a large number of mutations in the NB-ARC domain, but the rpml alleles show a high number of mutations throughout the NBARC region with very few mutations in the first portion of the
LRR. In contrast, the lov 1 alleles show a large number of mutations in the ARC1 and ARC2 domains and in the first portion of the LRR. LOVI shows fewer mutations in the NB region as compared with RPM1, although both genes show a peak of mutations in and around the P-loop at the beginning of the NB domain.

Although the distribution of mutations in the lov 1 versus rpml alleles appears only somewhat similar, a closer inspection of the mutations in the NB-ARC domain shows that both genes have mutations in or immediately adjacent to the P-loop, kinase 2, GLPL, and RNBS-D motifs (Fig. 2), which are conserved regions in the NB-ARC domain that have been found to be important for resistance-protein function (Dinesh-Kumar et al. 2000; Takken et al. 2006; Tao et al. 2000; Tornero et al. 2002). The lov 1 alleles also included one mutation in the RNBS-A motif, while RPM1 had mutations in the RNBS-B and RNBS-C motifs. Additionally, it is striking to note that in several cases, amino acids in corresponding positions of an
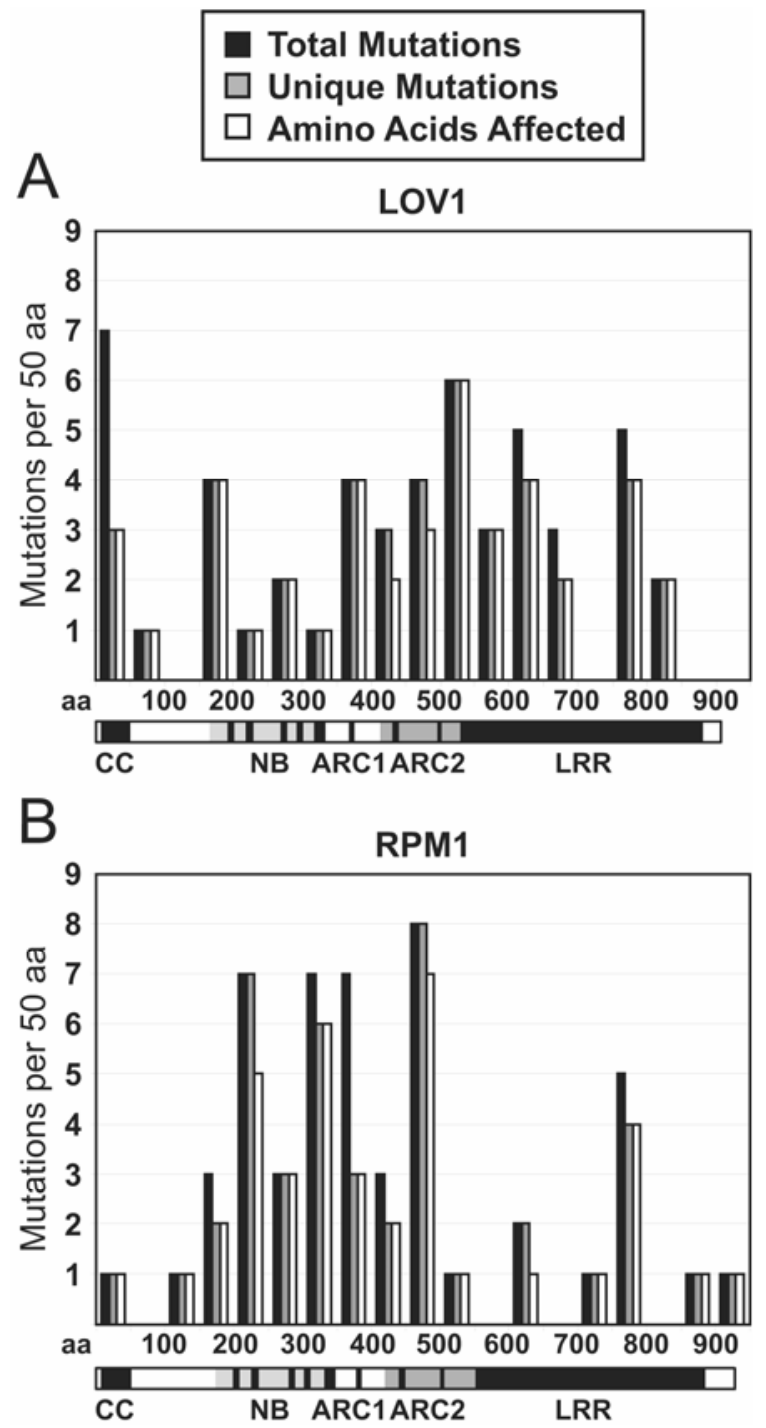

Fig. 1. Number of mutations in each 50-amino acid window of LOV1 and RPM1. The number of total and unique mutations and the number of amino acids affected in mutant alleles of A, LOV1 and B, RPM1 (from Tornero et al. 2002) were plotted in 50-amino acid windows. Diagrams under each graph represent the structure of each protein with the coiled-coil (CC), nucleotide binding (NB), ARC1, ARC2, and leucine-rich repeat (LRR) regions indicated. The smaller black rectangles represent conserved motifs within the NB-ARC domain. From left to right they are the P-loop, RNBS-A, kinase 2, RNBS-B, RNBS-C, GLPL, RNBS-D, and MHD motifs. 
alignment of LOV1 and RPM1 were found to be mutated in loss-of-function alleles of both genes (Fig. 2). These include LOV1 A370V (RPM1 A379V) in the GLPL motif and the nearby LOV1 G375R (RPM1 G384R); LOV1 A434T (RPM1
S439F) and LOV1 P437S/L (RPM1 P442L), both in the RNBSD motif; LOV1 G470R/E (RPM1 A474T); LOV1 A511T (RPM1 S515F); and LOV1 L777F (RPM1 L781F). In two cases, an amino-acid change in LOV1 that resulted in complete

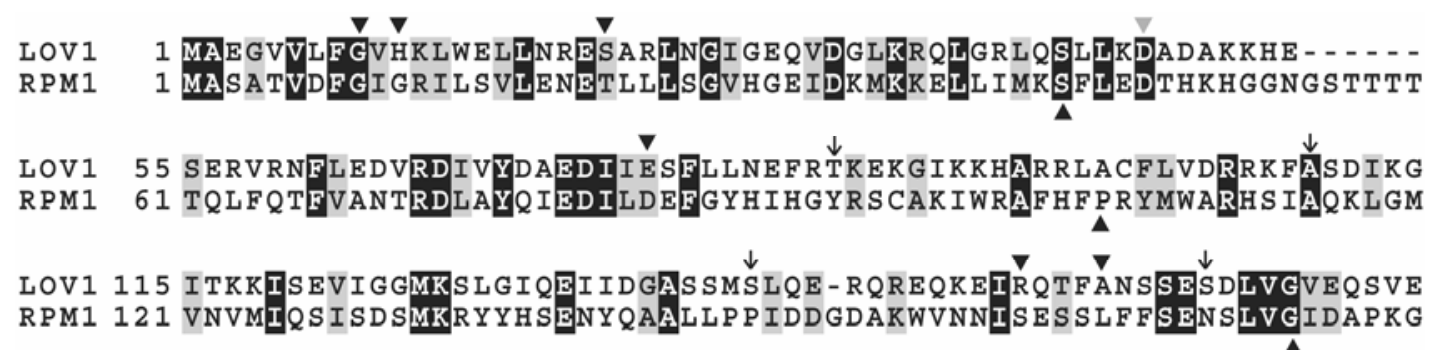
$\frac{\text { P-loop }}{\nabla} \quad \frac{\text { RNBS-A }}{\nabla} \downarrow$ LOV1 174 ALAGHLVEND-NIQVVSI S TMGGIGKTTLARQVFHHDMV̄QRHFDGFAWVFVSQQF TQKHV RPM1 $181 \mathrm{KLIGRLLSPEPQRIVVAVVGMGGSGKTTLSANIFKSQSVRRHFESYAWVTISKSYVIEDV}$ LOV1 233 WQRIWQELQPQNG - - - - - DISHMDEH ILQGKLFKLLETGRYLVVLDDVWKEEDWDRTKAV RPM1 241 FRTMIKEFYKEADTQIPAELYSLGYRELVEKLVEYLQSKRYIVVLDDVWTTGLWREIS IA

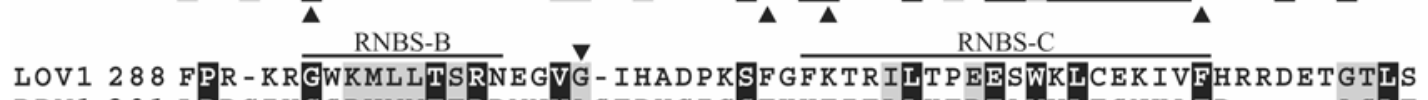
RPM1 301 LPDGIYGSRVMMTTRDMNVASFPYGIGSTKHEIELLKEDEAWVLFSNKAFP- - - ASLE LOV1 346 EVRVDEDMEAMGKEMVTCCGGLPLAVKVIGGLLATKHTVPEWKRVYDNIGPHLAGRSSLD RPM 156 QCRTQN - LEPIARKLVERCQGLPLAIASLGSMMSTKKFESEWKKVYSTLNWELNN - - - - N

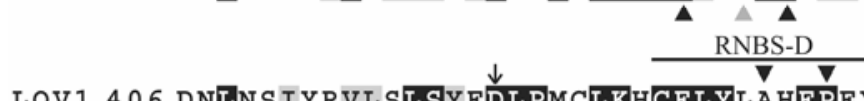
$\boldsymbol{\Delta}$

LAHFPEYYEIHVRRLFNYLAÄEGITSSDD $\stackrel{\downarrow}{\text { VTT T }}$ LOV1 406 DNLNS IYRVLSLSYEDLPMCLRHCFLYLAHFPEYYEIHVRRLFNYLAAEG I ITS SDDGTT
RPM1 411 HELKIVRSIMFLSFNDLPYPLKRCFLYCSLFPVNYRMKRKRLIRMWMAQRFVEPIR-GVK

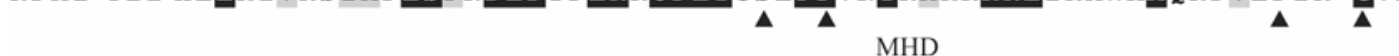
LOV1 466 IQDKGEDYLEELARRNMITIDKNYMFLRKRHCQM̈HDMMREVCLSKÁREENFLEIFK - VST RPM1 470 AEEVADSYLNELVYRNMLQVILWNPFGRPKAFKMHDVIWEIALSVSKLERECDVYNDDSD LOV1 525 ATSAINARSLSKSRRLSVHGGNALSLGOTINKKVRSLLYFAFEDEFCILESTTPCFRSL RPM1 530 GDDAAETMENYGSRHLCIQKEMTPDSIRATN - - - LHSLLVCS SAKHKMELLP - - - - SL LOV1 585 PLLRVLDLSRVKFEGGKLPSSIGDLIHLRFLSLHRAWI SHLPS SLRNLKLLLYLNLGFNG RPM 1581 NLLRALDLEDS IS - -KLPDCLVTMFNLKYLNLSKTQVKELPKNFHKLVNLETLNTKHSK LOV1 645 MVHVPNVLKEMQELRYLQLP - . - . - . - MSMHDKTKLELSDLVNLESLMNFSTKYAS RPM1 639 IEELPLGMWKLKKLRYLITFRRNEGHDSNWNYVLGTRVVPKIWQLKDLQVMDCFNAEDEL

LOV1 694 VMDLLHMTKLRELSLFITDGSS-DTLSSSLGQLRSLEVUHLYDRQEPRVAYHGGEIVLNC RPM1 699 IKNLGCMTQLTRISLVMVRREHGRDLCDSLNKIKRIRFLSLTSIDEE - - EPLEIDDLIAT LOV1 753 IHLKELELAIHMPRFPDQYLFHPHLSH IYLWCCSMEEDPIPILERLLHLKSVILTFGAFV RPM1 757 ASIEKLFLAGKLERVPSWFNTLQNLTYLGLRGSQLQENAILSIQTLPRLVWLSFYN-AYM $\boldsymbol{\nabla}$

LOV1 813 GRRMVCSKGGFPQLCFLKLEELEELEEWIVEEGSMPLLRALT I CNCRKLK - LPGGINYIT RPM1 816 GPRLRFAQ-GFQNLKILEIVQMKHLTEVVIEDGAMFELQKLYVRACRGLEYVPRGIENLI LOV 1872 SLKELTIVGMKWKEKLVPGGE- - -DYYKVVNIP $\stackrel{\downarrow}{\downarrow}$ NVQFINCDE - - - - - . - . RPM 1875 NLQELHLIHVSNQLVERIRGEGSVDRSRVKHIPAIKHYFRTDNGSFYVSLSS

Fig. 2. Alignment of LOV1 and RPM1 protein sequences indicating position of substitutions causing loss of function of LOV1 and RPM1 and natural polymorphisms found in LOV1. An amino-acid alignment of LOV1 and RPM1 was created using ClustalW. The position of missense mutations leading to loss of function of each protein are indicated by triangles, black for complete loss of function and gray for partial loss of function. Data for the rpm1 mutant alleles was obtained from Tornero and associates (2002). Arrows denote the positions of nonsynonymous polymorphisms found in LOV1 alleles from different Arabidopsis thaliana ecotypes in comparison to the $\mathrm{Cl}-0$ allele used in the alignment. Thin arrows denote polymorphisms resulting in single aminoacid changes found in ecotypes that retain sensitivity to victorin. Bold arrows denote polymorphisms found only in insensitive ecotypes. Conserved motifs within the nuceotide-binding (NB)-ARC domain are marked by lines over the motifs. For this study, the major domains of LOV1 were considered to encompass the following residues: coiled coil $=1-51 ; \mathrm{NB}=167-324 ; \mathrm{ARC} 1=325-412 ; \mathrm{ARC} 2=413-530$; leucine-rich repeat $=531-878$. 
loss of function resulted in only partial loss of function when the corresponding amino acid was mutated in RPM1. These are LOV1 G192E (RPM1 G200E) in the P-loop and LOV1 G822D (RPM1 G824E). These nine amino-acid positions that affect function of both LOV1 and RPM1 may be particularly important for the activity of CC-NB-LRR proteins, especially considering that five of them fall in or near conserved motifs of the NB-ARC domain and that two different amino-acid substitutions at residues 437 and 470 both eliminated function of LOV1. Alternatively, some of these amino acids may be required for the stability of CC-NB-LRR proteins.

\section{Comparison to RPP8 family members.}

The genes most closely related to LOVI that are known to function in disease resistance are the $R P P 8$ family members. These include the genes $R P P 8$, which confers resistance to Hyaloperonospora parasitica isolate Emco5 in the Arabidopsis ecotype Landsberg erecta (McDowell et al. 1998), RCY1, which confers resistance to the yellow strain of Cucumber mosaic virus in ecotype C24 (Takahashi et al. 2002), and $H R T$, which is involved in resistance to Turnip crinkle virus in the Dijon ecotype (Cooley et al. 2000). RPPS, RCY1, and HRT are allelic to each other and share 91 to $92 \%$ amino-acid identity (95 to $96 \%$ similarity) in pairwise alignments. LOV1 is not allelic to these three genes but shows approximately $70 \%$ identity ( $86 \%$ similarity) to each of these genes at the amino-acid level. An alignment of the RPP8 family members with LOV1 shows that, of the 910 amino-acid residues in the LOV1 coding region, $615(67.6 \%)$ are identical between LOV1 and all three of the RPP8 family members. These conserved residues accounted for 35 out of $42(83.3 \%)$ of the residues that were mutated in the lov1 loss-of-function alleles. Conversely, 195 LOV1 residues $(21.4 \%)$ are not identical to the corresponding residue in any of the other three proteins. However, these residues accounted for only five $(11.9 \%)$ of the mutated residues in the loss-of-function alleles. The remaining two mutations were in amino-acid residues identical between LOV1 and at least one of the RPP8 family members. This skew towards mutation of conserved residues suggests that most of the mutations uncovered in this study might result in loss of function of any of the RPP8 family members and may affect conserved NB-LRR gene functions or protein stability. In contrast, the five mutations in residues unique to LOV1 may define amino acids specifically important for direct or indirect perception of victorin or for interaction with unique downstream signaling partners. These five mutations (H11Y, A158V, G544D, G644E, and S666L) were not clustered together in the protein sequence. However, three of them are located in the LRR region of the protein, which is generally the most variable portion of resistance genes and, in several cases, has been found to determine resistance-gene specificity (Dodds et al. 2001; Ellis et al. 1999; Zhou et al. 2006), and one is located in the CC domain, which is thought to be involved in interaction with signaling partners (Belkhadir et al. 2004).

\section{Sampling of natural $L O V 1$ allelic diversity.}

The original study that identified victorin sensitivity in Arabidopsis suggested that sensitivity is relatively rare with only six out of 433 seed populations characterized as containing individuals that were clearly sensitive to victorin (Lorang et al. 2004). However, we have since determined that seedlings are typically much less sensitive to victorin than adult plants (Sweat and Wolpert 2007). As seedlings were employed in the initial screen, this raised the possibility that many sensitive ecotypes were overlooked. Therefore, in addition to the original six sensitive ecotypes and the insensitive ecotype Col-4 reported in the first study, we obtained seed from 23 additional ecotypes and tested all 30 ecotypes by the detached-leaf assay, in which a leaf from a mature plant is removed and placed in a solution of victorin for 3 days. At least eight individuals of each ecotype were tested, except in the few cases in which

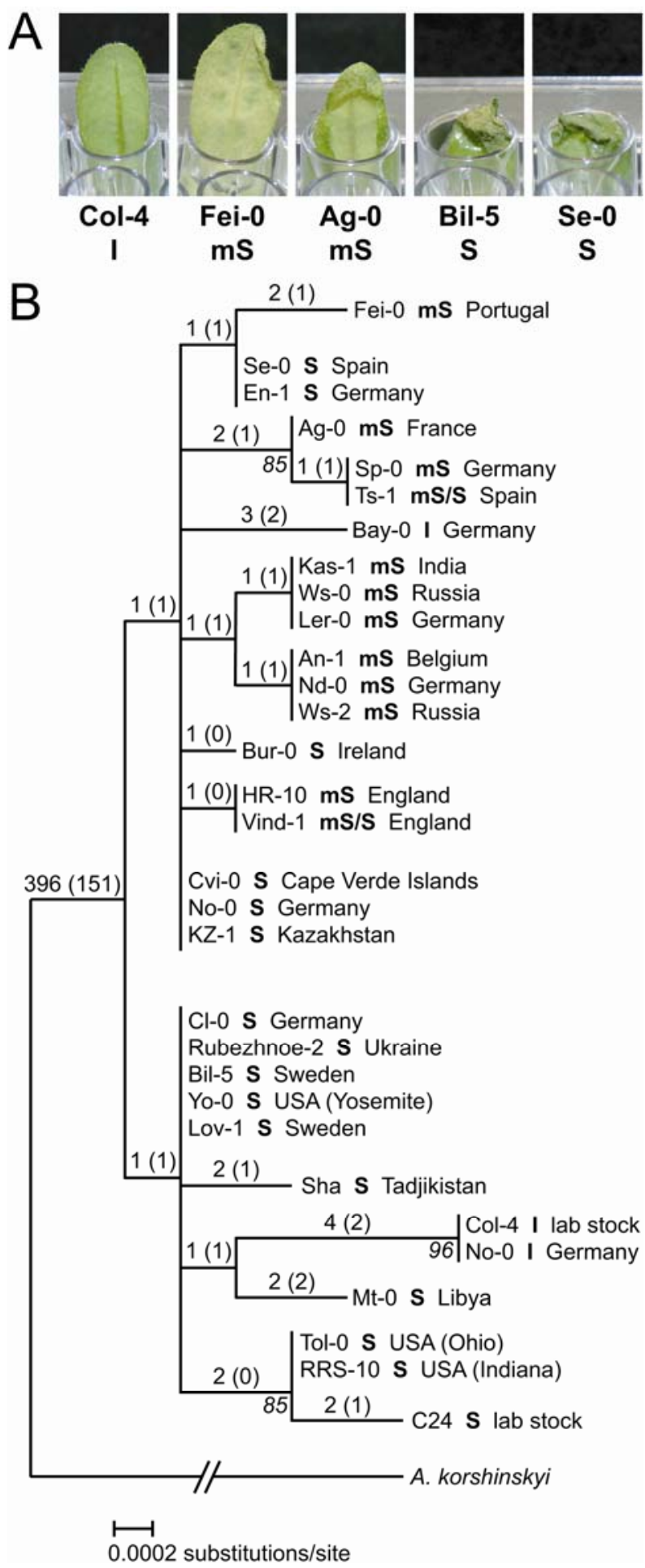

Fig. 3. Analysis of ecotype variation in victorin sensitivity and LOV1 allele sequence. A, Representative leaves showing symptoms on victorin insensitive (I), moderately sensitive $(\mathrm{mS})$, and highly sensitive (S) ecotypes two days after treatment with $10 \mu \mathrm{g}$ of victorin per milliliter. B, Neighbor-joining tree (500 bootstraps) based on the entire sequenced region (coding and noncoding) of LOV1. The victorin-sensitivity phenotype of each ecotype is indicated in bold. The origin of each ecotype is also indicated. Numbers above each branch indicate the number of mutations with the number of nonsynonymous substitutions in parentheses; bootstrap values $>80 \%$ are indicated below the branches in italics. 
poor seed germination precluded screening eight individuals. Leaves were scored for symptom development at 1, 2, and 3 days after victorin treatment. Somewhat surprisingly, we found that nearly all ecotypes showed some level of sensitivity to victorin (Fig. 3). The only plants that were completely insensitive, besides Col-4, were Bay-0 and some individuals of the No-0 ecotype, which was the only ecotype found to have both victorin-sensitive and -insensitive individuals. The sensitive ecotypes were compared with the ecotype $\mathrm{Cl}-0$, from which the LOV1 gene was originally cloned (Lorang et al. 2007), in order to evaluate levels of sensitivity to victorin. Because the timing of the response to victorin tends to be somewhat variable between experiments, we only attempted to define two categories of sensitivity (Fig. 3A). Ten ecotypes reproducibly displayed low to moderate levels of sensitivity $(\mathrm{mS})$, showing no or only very slight symptoms until at least two days after treatment with victorin and usually showing only yellowing or partial collapse on day 3. Sixteen ecotypes, including Cl-0 and the sensitive No-0 individuals, consistently showed visible symptoms by day 1 and generally showed complete collapse of the leaf by day 3. Not surprisingly, five of the six accessions originally described as being sensitive to victorin (Lorang et al. 2004) fell into this highly sensitive (S) category. Two ecotypes, Ts-1 and Vind-1, could not be placed conclusively in either of these categories because, in repeated experiments, about half the leaves from each ecotype showed symptoms on day 1 while the other leaves took longer to develop symptoms. This was true even when multiple leaves from the same individual were sampled, indicating that it is not a genotypic difference. Rather, it is likely due to these ecotypes expressing levels of sensitivity very near the threshold required for symptom development within one day. These were, therefore, categorized as $\mathrm{mS} / \mathrm{S}$. We also tested for victorin sensitivity in the related species Arabidopsis suecica, Arabidopsis korshinskyi (also called Olimarabidopsis cabulica), Olimarabidopsis pumila, Arabidopsis arenosa, Crucihimalaya lasiocarpa, and Capsella rubella. All other species tested were completely insensitive to victorin with the exception of A. suecica, which showed very low levels of sensitivity.

\section{Sequencing of $L O V 1$ alleles from A. thaliana ecotypes.}

The LOV1 gene was sequenced from each of the evaluated ecotypes and the polymorphisms present were compared with the Cl-0 allele (Supplementary Table S2). The sequenced region spanned from $272 \mathrm{bp}$ upstream of the start codon to 149 bp downstream of the stop codon $(3,388 \mathrm{bp}$ total). Four ecotypes (Rubezhnoe-2, Bil-5, Yo-0, and Lov-1) were found to carry an allele identical to the $\mathrm{Cl}-0$ allele, and the allele found in two other ecotypes (Tol-0 and RRS-10) differed only by silent changes. The other sensitive ecotypes had two to five polymorphisms compared with $\mathrm{Cl}-0$, causing one to four amino-acid substitutions. The Col-4 allele, which is identical to the published Col-0 sequence, showed six nucleotide differences when compared with the Cl-0 LOVI gene (Lorang et al. 2007). The insensitive individuals from the No-0 ecotype had an allele identical to that of Col-4. We therefore considered the possibility that these insensitive No-0 individuals could be the result of seed contamination from Col-0 or Col-4. We analyzed 13 simple sequence-length polymorphism (SSLP) markers scattered throughout the genome, including one SSLP tightly linked to LOV1, marker 3571, and 13 unlinked markers, and we compared the SSLP pattern of the sensitive and insensitive No-0 individuals with each other and with Col-4. One marker was not polymorphic between any of the three individuals. The remaining markers were all polymorphic between Col-4 and both No-0 individuals. Of these 12 markers, eight, including the SSLP linked to LOV1, gave PCR products of the same size in both the No-0 individuals, while four were polymorphic between the sensitive and insensitive individuals (data not shown). These data indicate that the insensitive and sensitive No-0 individuals are related and not due to seed contamination, although there is apparently a relatively large amount of genetic variation within this accession. The only other insensitive ecotype, Bay-0, has an allele that encodes a full-length protein with five nucleotide polymorphisms compared with $\mathrm{Cl}-0$.

\section{Evaluation of the insensitive alleles.}

Of the six nucleotide changes present between the Col-4 and Cl-0 LOVI alleles, two do not affect the amino-acid sequence. Of the remaining four differences, two result in amino-acid substitutions (D421N and Q549P). The other two differences cause truncation of the protein. The $621 \mathrm{~A}$ to $\mathrm{T}$ mutation results in a stop codon at lysine 117, and the deletion of a nucleotide at 3,042 results in a frameshift at codon 846 , which would cause the addition of seven incorrect amino acids and a premature stop. Portions of the Col-4 lovl allele were swapped with portions of the Cl-0 LOVI gene in order to assess the individual effects of the four differences that result in an altered protein product. It was found that either of the nucleotide substitutions causing truncation of the protein were sufficient to eliminate LOV1 function when present individually. In order to evaluate the effects of the two amino-acid substitutions, the central portion of the Cl-0 LOVI gene was replaced with the portion of the Col-4 allele carrying the two differences. This was also found to eliminate LOV1 function. These base pair changes were not evaluated individually in this experiment. However, the D421N amino-acid substitution was also found to be present in ecotype Mt-0, which is sensitive to victorin. Therefore, the Q549P change appears to be responsible for the loss of sensitivity, which is not unexpected, given that it is a very nonconservative change and is in a region near other mutations that were found to result in loss of LOV1 function (Fig. 2). Four of the five polymorphisms in the Bay-0 ecotype result in amino-acid substitutions. Of these, two (T86A and A109D) are present in many other ecotypes belonging to both the $\mathrm{S}$ and $\mathrm{mS}$ phenotypic groups and apparently do not reduce sensitivity to victorin. Of the other two amino-acid changes, one (R538S) is between two amino acids found to affect victorin sensitivity when mutated, partial loss in the case of S537F and complete loss for R539K (Fig. 2). This suggests that the R538S substitution may be responsible for the insensitive phenotype of Bay0 . However, the other substitution (T228A) in the Bay-0 allele is immediately adjacent to the RNBS-A domain and could lead to loss of function either on its own or in combination with R538S.

\section{Polymorphisms in sensitive alleles.}

The phylogeny of LOVI alleles divides them into two major clades (Fig. 3B). However, these clades are not strongly supported by the bootstrap analysis and are separated by only two polymorphisms, both of which cause amino-acid substitutions (T86A and A109D) in a comparison of the upper group with the lower group. As mentioned above, these two polymorphisms are present in alleles belonging to each phenotypic class ( $\mathrm{S}, \mathrm{mS}$, and I [victorin insensitive]) and, therefore, do not appear to affect the victorin response. All ecotypes belonging to the $\mathrm{mS}$ group are found in the upper group, but these LOVI alleles all contain additional polymorphisms that likely play a role in reducing sensitivity (Fig. 3B). Although, in actuality, the sensitive ecotypes represent a continuum of phenotypes from slightly sensitive to highly sensitive to victorin, the division of these ecotypes into two primary groups ( $\mathrm{mS}$ and $\mathrm{S}$ ) allows information to be gleaned regarding the relationship between the sequence of $L O V I$ and the level of sensitivity dis- 
played. In general, there is a very strong correlation between genotype and phenotype, although there are exceptions. In two cases (Sp-0/Ts-1 and HR-10/Vind-1), ecotypes with identical alleles show slightly different levels of sensitivity. This could be due to variation in LOV1 expression between the ecotypes or possibly due to differences in modifying genes or differences in plant morphology that cause a decrease in the appearance of symptoms due to effects not specific to the victorin response pathway. A similar situation was observed when the Cl-0 LOV1 allele was introgressed into the Col-4 background. This line, Col-LOV, showed slightly reduced sensitivity to victorin compared with the $\mathrm{Cl}-0$ parent, indicating that ecotype background differences can influence victorin sensitivity (Sweat and Wolpert 2007). The HR-10/Vind-1 allele is also identical to the Bur-0, Cvi-0, No-0 (S), and KZ-1 alleles at the amino-acid level. As these other ecotypes fall into the $S$ category, it appears that HR-10 $(\mathrm{mS})$ and Vind-1 $(\mathrm{mS} / \mathrm{S})$ may have reduced expression or other background differences that result in reduced sensitivity to victorin. However, in the case of the clade containing six moderately sensitive (mS) ecotypes, Kas1 , Ws- 0 , Ler- 0 , An- $1, \mathrm{Nd}-0$, and Ws-2, the difference in sensitivity is likely caused by the $\mathrm{N} 481 \mathrm{H}$ polymorphism present in all of these ecotypes, which is adjacent to the R480K loss-offunction mutation found in allele lov $1-11$, although each ecotype also contains another nonsynonymous polymorphism that could contribute to the phenotype. The moderately sensitive phenotype of the Fei-0 ecotype is likely due to the M499I polymorphism, which falls within the conserved MHD motif. None of the ecotypes tested showed polymorphisms at any of the amino-acid residues mutated in the LOV1 loss-of-function screen (Fig. 2).

\section{Geographic differentiation.}

We noted three pairs of ecotypes from the same region that share identical LOV1 alleles, Lov-1 and Bil-5 from northern Sweden, Tol-0 and RRS-10 from the midwestern United States, and HR-10 and Vind-1 from England (Fig. 3B). This is in line with work showing that individuals collected from different populations within a region tend to be more related than individuals from different geographic regions (Bakker et al. 2006a; Nordborg et al. 2005). This was particularly noted with populations from the midwestern United States, which tend to be highly related. However, in general, our results do not show a strong geographic correlation, as many of the alleles are present in ecotypes from very diverse geographic regions. This is also consistent with previous studies, which found that most genetic variation occurs within geographic regions (Bakker et al. 2006a; Nordborg et al. 2005), such that geographic structure would not be expected to be evident in studies focusing on relatively small samples and a single gene. A similar study of the RPS2 resistance gene also did not find any allelic differentiation among regions (Mauricio et al. 2003).

\section{Sequencing of $L O V 1$ from other species.}

Using the original sets of PCR primers (discussed below), the only species besides A. thaliana to give a complete LOVI sequence was $A$. suecica, which was also the only other species to show a response to victorin. We sequenced the LOVI allele from three accessions of A. suecica (CS22505, CS22507, and CS22511) and found all three to be identical to the allele from the A. thaliana Sha ecotype. However, while the Sha ecotype shows high levels of sensitivity, A. suecica is only slightly sensitive to victorin. A. suecica accession CS22511 showed a somewhat stronger response to victorin than the other two accessions but was still reduced in comparison to the Sha ecotype. Whether these variations in sensitivity are due to different levels of gene expression or to the presence of other genes that modify the phenotype is unknown. We also sequenced the ATTRX5 gene, which is required for the victorin response (Sweat and Wolpert 2007), from A. suecica and found that it is identical to that found in both the Col-4 and Cl0 ecotypes. The high similarity of the LOV1 gene between $A$. suecica and $A$. thaliana alleles is likely due to the origin of $A$. suecica as an allopolyploid between $A$. thaliana and $A$. arenosa (Mummenhoff and Hurka 1995). As we were unable to amplify the complete $A$. arenosa LOVI allele with our primers, the product obtained from $A$. suecica likely came from the A. thaliana ancestral parent.

Because the A. suecica allele does not represent a true outgroup, we used partial LOVI sequences obtained from A. korshinskyi to design new PCR primers to amplify the remainder of the LOVI sequence. We chose this species because the initial PCR of this allele resulted in the most successful amplification products of all the tested species. Using newly designed primers, we were also able to amplify the entire LOVI allele from Olimarabidopsis pumila and found it to be nearly identical to the A. korshinskyi allele, differing at only seven nucleotide positions. The $A$. korshinskyi allele is $85.5 \%$ identical to the $\mathrm{Cl}-0$ allele across the entire sequenced region at the nucleotide level and $82.8 \%$ identical $(89.9 \%$ similar) at the amino-acid level. Excluding sites with gaps, there are 257 fixed differences in the coding sequence between A. korshinskyi and all $A$. thaliana LOV1 alleles. These include 106 synonymous and 151 nonsynonymous (amino acid changing) fixed differences. The A. korshinskyi allele encodes a fulllength protein, and the domains known to be critical for NBLRR gene function (e.g., the P-loop and kinase 2 motifs) appear to be intact. Therefore, the A. korshinskyi allele appears to encode a functional NB-LRR protein, which is likely too divergent to function in the victorin response pathway. In support of this is the observation that three residues found to cause partial or complete loss of victorin sensitivity when mutated in the A. thaliana $\mathrm{Cl}-0$ allele are substituted in the $A$. korshinskyi sequence. One of these residues is located in the CC domain and the other two are in the LRR region and could, therefore, disrupt victorin recognition or signaling pathways, as these regions are thought to be important for determining recognition specificity and interacting with signaling proteins (Belkhadir et al. 2004).

\section{Population genetic analysis of $L O V 1$ alleles.}

Within the A. thaliana ecotypes there are 29 polymorphic sites, excluding the two sites with gaps (Table 1). These consist of 18 nonsynonymous (amino acid changing) polymorphisms, five synonymous changes, and six polymorphisms that fall outside the coding region. When standardized for the sequence length (3,386 bp excluding gaps), this gives a value of 0.0086 segregating sites per base pair. This is a relatively low number of segregating sites compared with that seen in other NB-LRR genes previously studied in Arabidopsis (Bakker et al. 2006b; Mauricio et al. 2003; Rose et al. 2004). However, these segregating sites result in 16 different haplotypes at the nucleotide level encoding 13 protein variants. This is also reflected in the nucleotide diversity $(\pi)$, which is on the low end of the spectrum compared with other NB-LRR genes (Bakker et al. 2006b; Mauricio et al. 2003; Rose et al. 2004). Over the entire sequenced region, $\pi=0.00126$ and, in the coding region, $\pi=$ 0.00131 . At nonsynonymous sites, $\pi_{a}=0.00143$, while $\pi_{s}=$ 0.00093 at synonymous sites, indicating an excess of nonsynonymous compared with synonymous diversity $\left(\pi_{a} / \pi_{s}=1.54\right)$, in line with the relatively large number of encoded protein variants. Dividing the LOV1 gene into functional regions showed that the highest nucleotide diversity at nonsynonymous sites $\left(\pi_{a}\right)$ fell in regions outside of those with well-char- 
acterized roles in NB-LRR gene function. In particular, $\pi_{a}=$ 0.00477 between the $\mathrm{CC}$ and $\mathrm{NB}$ domains and $\pi_{a}=0.00798$ between the last structural residue of the LRR region and the end of the protein. The ARC2 region also showed a higher than average nucleotide diversity at nonsynonymous sites $\left(\pi_{a}=\right.$ 0.00228). In contrast, the CC, NB, ARC1, and LRR domains showed relatively low values of nonsynonymous nucleotide diversity $\left(\pi_{a}=0-0.00066\right)$. Pairwise $K_{a} / K_{s}$ comparisons, excluding the truncated Col-4 and No-0 (I) alleles and any pairwise comparisons with $K_{s}=0$, showed the highest $K_{a} / K_{s}$ ratio $\left(K_{a} / K_{s}=2.06\right)$ between the Mt-0 and Fei-0 alleles. Although this ratio significantly exceeds the threshold of $K_{a} / K_{s}>1$, as identified by K-estimator (Comeron 1999), which is considered to be a sign of balancing selection within a species, the result was not significant after Bonferroni correction, which accounts for the number of pairs tested. This lack of statistical significance is likely due to the low overall levels of polymorphism in the gene.

Analysis of $K_{a} / K_{s}$ ratios between $A$. korshinskyi and $A$. thaliana alleles gave a Jukes Cantor corrected $K_{a}=0.0769$ and $K_{s}=0.2000\left(K_{a} / K_{s}=0.3842\right)$ in the coding region (Table 2). A McDonald-Kreitman test of intraspecies polymorphism versus divergence between species at synonymous and nonsynonymous sites (McDonald and Kreitman 1991) fails to reject the hypothesis of neutral evolution $(p=0.077)$, again likely due to the low numbers of polymorphisms present in the LOVI A. thaliana alleles. In the between species comparison, no functional region was observed to have a $K_{a} / K_{s}$ ratio $>1$ and the LRR region showed a slightly lower than average $K_{a} / K_{s}$ ratio of 0.3473 (Table 2). The solvent-exposed, hypervariable residues (x) of the xxLxLxx motif are thought to be important for mediating the specificity of protein interactions with the LRR
(Jones and Jones 1997) and show evidence of being under positive selection in many resistance genes (Bergelson et al. 2001; Mondragón-Palomino et al. 2002). For LOV1, the interspecies $K_{a} / K_{s}$ ratio equals 0.933 for these residues, which is much higher than the average across the entire gene and the LRR as a whole but still below the threshold of $K_{a} / K_{s}>1$ indicative of positive selection.

\section{DISCUSSION}

Several lines of evidence suggest that LOV1, although it confers susceptibility to infection by the fungus $C$. victoriae, functions in a manner analogous to a resistance protein. As described above, the spectrum of mutations found to result in loss of function of LOV1 shows many similarities to those mutations found to disrupt the function of RPM1, another CCNB-LRR protein (Tornero et al. 2002). In particular, several residues at corresponding positions of LOV1 and RPM1 were observed to be mutated in both studies (Fig. 2), suggesting that these two proteins may function in a similar manner. In addition, both studies uncovered mutations in many of the motifs of the NB-ARC domain that are conserved among NB-LRR proteins (Fig. 2) and are important for resistance protein function, likely due to a role in the binding and hydrolysis of ATP (Takken et al. 2006; Tameling et al. 2002, 2006). For LOV1, $8.4 \%$ of these residues ( 7 of 83 ) were affected by loss-of-function mutations, in comparison to $4.2 \%$ of all other residues $(35$ of 827 ) and $3.9 \%$ of other residues in the NB-ARC domain (11 of 281), indicating that mutation of these conserved residues is about twice as likely to cause loss of LOV1 function, assuming equal chances of these residues undergoing mutagenesis. Additionally, LOV1 is highly related to the RPP8 family members

Table 1. Nucleotide diversity and segregating sites in functional regions of $L O V 1$

\begin{tabular}{|c|c|c|c|c|c|c|c|c|}
\hline Region $^{a}$ & Position & Length $^{b}$ & $\pi^{\mathrm{c}}$ & $S_{\text {total }}{ }^{d}$ & $\pi_{\text {silent }}{ }^{\mathrm{c}}$ & $S_{\text {silent }}{ }^{d}$ & $\pi_{\text {nonsyn }}{ }^{c}$ & $S_{\text {nonsyn }}{ }^{d}$ \\
\hline Entire region & 1 to 3,388 & 3,386 & 0.00126 & $29(0.0086)$ & 0.00098 & 11 & 0.00143 & 18 \\
\hline Coding & 273 to 3,236 & 2,729 & 0.00131 & $23(0.0084)$ & 0.00093 & 5 & 0.00143 & 18 \\
\hline Coiled-coil & 273 to 425 & 153 & 0.00000 & $0(0.0000)$ & 0.00000 & 0 & 0.00000 & 0 \\
\hline $\mathrm{CC}$ to $\mathrm{NB}$ & 426 to 770 & 345 & 0.00375 & $5(0.0145)$ & 0.00000 & 0 & 0.00477 & 5 \\
\hline NB & 771 to $1,149+1,300$ to 1,394 & 474 & 0.00078 & $3(0.0063)$ & 0.00126 & 1 & 0.00066 & 2 \\
\hline ARC1 & 1,395 to $1,458+1,543$ to 1,742 & 264 & 0.00024 & $1(0.0038)$ & 0.00111 & 1 & 0.00000 & 0 \\
\hline ARC2 & 1,743 to 2,096 & 354 & 0.00179 & $4(0.0113)$ & 0.00000 & 0 & 0.00228 & 4 \\
\hline LRR & 2,097 to 3,140 & 1,043 & 0.00054 & $5(0.0048)$ & 0.00127 & 2 & 0.00032 & 3 \\
\hline LRR to stop & 3,141 to 3,236 & 96 & 0.00699 & $5(0.0521)$ & 0.00346 & 1 & 0.00798 & 4 \\
\hline $5^{\prime}$ noncoding & 1 to 272 & 271 & 0.00181 & $4(0.0148)$ & 0.00181 & 4 & NA & NA \\
\hline Intron 1 & 1,150 to 1,299 & 150 & 0.00083 & $1(0.0067)$ & 0.00083 & 1 & NA & NA \\
\hline Intron 2 & 1,459 to 1,542 & 84 & 0.00000 & $0(0.0000)$ & 0.00000 & 0 & NA & NA \\
\hline $3^{\prime}$ noncoding & 3,237 to 3,388 & 152 & 0.00042 & $1(0.0066)$ & 0.00042 & 1 & NA & NA \\
\hline
\end{tabular}

${ }^{\text {a }} \mathrm{CC}=$ coiled-coil; $\mathrm{NB}=$ nucleotide binding; and LRR = leucine-rich repeat.

${ }^{\mathrm{b}}$ Length in base pairs, excluding sites with gaps.

${ }^{\mathrm{c}}$ Nucleotide diversity, as determined by DnaSP 4.10 (Rozas et al. 2003).

${ }^{d}$ Number of segregating sites. Numbers in parentheses are standardized by sequence length.

Table 2. Analysis of divergence between Arabidopsis thaliana and A. korshinskyi LOV1 alleles

\begin{tabular}{|c|c|c|c|c|c|c|c|c|c|}
\hline Region & Position & $\mathbf{N}_{\mathrm{s}}{ }^{\mathrm{a}}$ & $\mathbf{D}_{\mathrm{s}}^{\mathbf{b}}$ & $K_{s}(\mathrm{JC})^{\mathrm{c}}$ & $\mathbf{N}_{a^{a}}$ & $\mathbf{D}_{\mathbf{a}}{ }^{\mathrm{b}}$ & $K_{a}(\mathrm{JC})^{\mathrm{c}}$ & $D_{x y}^{d}$ & $K_{a} / K_{s}$ \\
\hline Coding & 1 to 2,772 & 599.7 & 106 & 0.2000 & 2109.3 & 151 & 0.0769 & 0.0961 & 0.3842 \\
\hline Coiled-coil & 1 to 1,53 & 37.3 & 8 & 0.2526 & 115.7 & 4 & 0.0354 & 0.0784 & 0.1402 \\
\hline $\mathrm{CC}$ to $\mathrm{NB}$ & 154 to 498 & 71.9 & 10 & 0.1538 & 273.1 & 21 & 0.0859 & 0.0932 & 0.5583 \\
\hline NB & 499 to 972 & 99.9 & 15 & 0.1684 & 374.1 & 24 & 0.0674 & 0.0827 & 0.4004 \\
\hline ARC1 & 973 to 1,239 & 55.1 & 7 & 0.1291 & 196.9 & 13 & 0.0719 & 0.0795 & 0.5567 \\
\hline ARC2 & 1,240 to 1,596 & 75.2 & 16 & 0.2411 & 275.8 & 28 & 0.1127 & 0.1281 & 0.4674 \\
\hline LRR & 1,597 to 2,670 & 241.2 & 46 & 0.2210 & 796.8 & 58 & 0.0768 & 0.1010 & 0.3473 \\
\hline LRR to stop & 2,671 to 2,772 & 19.2 & 4 & 0.2472 & 76.9 & 3 & 0.0445 & 0.0766 & 0.1801 \\
\hline
\end{tabular}

${ }^{a}$ Estimated number of synonymous $\left(\mathrm{N}_{\mathrm{s}}\right)$ and nonsynonymous $\left(\mathrm{N}_{\mathrm{a}}\right)$ sites.

${ }^{\mathrm{b}}$ Number of fixed differences between species at synonymous $\left(\mathrm{D}_{\mathrm{s}}\right)$ and nonsynonymous $\left(\mathrm{D}_{\mathrm{a}}\right)$ sites

c Jukes-Cantor corrected synonymous differences per synonymous site $\left(K_{s}\right)$ and nonsynonymous differences per nonsynonymous site $\left(K_{a}\right)$.

${ }^{\mathrm{d}}$ Average number of nucleotide substitutions per site between species. 
(RPP8, RCY1, and HRT), which all have known functions in resistance (Cooley et al. 2000; McDowell et al. 1998; Takahashi et al. 2002), and the residues that were found to be substituted in the nonfunctional lov 1 alleles were skewed towards residues that are conserved between LOV1 and all three of the RPP8 family members.

The results obtained with LOV1 are consistent with the results of mutagenesis screens performed on other NB-LRR genes that function in resistance, further suggesting that LOV1 functions in a manner analogous to resistance proteins. Therefore, our mutagenesis study of LOV1 adds to the data from other studies that have helped elucidate the structure-function relationship of NB-LRR proteins. For example, the two mutations in the P-loop of LOV1 that resulted in loss of function (G192E and T199I) also resulted in loss of function when the corresponding amino acids were mutated in the TIR-NB-LRR tobacco $N$ gene product $(\mathrm{G} 216 \mathrm{~A} / \mathrm{E} / \mathrm{V} / \mathrm{R}$ and $\mathrm{T} 223 \mathrm{~A} / \mathrm{N})$ (Dinesh-Kumar et al. 2000), further confirming the importance of these residues in NB-LRR protein function. Another largescale mutant screen was performed by Bendahmane and associates (2002) on the CC-NB-LRR gene $R x$, which confers resistance to Potato virus $X$ (Bendahmane et al. 1999). This screen was designed to look for gain-of-function mutations that result in an HR in the absence of elicitor. Seven such mutations were uncovered (Bendahmane et al. 2002). Of these, three were in the RNBS-D motif, leading the authors to speculate that this serves as a negative regulatory region. However, mutation of amino acids at two other positions in this motif led to loss of function of both LOV1 and RPM1 (discussed above), suggesting that the RNBS-D motif is not solely important as a negative regulatory region. Mutations within the conserved MHD motif, specifically the histidine residue in the L6 protein and the aspartic acid residue in the $\mathrm{Rx}, \mathrm{I}-2$, and L6 proteins, have been reported to cause gain-of-function phenotypes (Bendahmane et al. 2002; De la Fuente van Bentem 2005; Howles et al. 2005). Consistent with these findings, mutation of these residues did not show up in our loss-of-function screen for LOV1 or in the RPM1 study (Tornero et al. 2002), although mutation of nearby residues in both proteins did result in loss of function. Mutation of the methionine of the MHD motif to a lysine resulted in loss of function of the L6 protein (Howles et al. 2005). This is consistent with the conjecture that the M499I polymorphism in the MHD motif of LOV1 is responsible for the reduced sensitivity of the Fei-0 ecotype. The other three mutations found to cause elicitor-independent activation of $\mathrm{Rx}$ occurred in the LRR domain (Bendahmane et al. 2002). One of these was a D543E mutation in the VLDL motif conserved in LRR3 of many resistance genes. Interestingly, the VLDL motif is conserved in LOV1 and mutation of the corresponding aspartate (D591N) caused loss of function of LOV1. Whether this difference is due to differences in the function of these genes or to the difference in the substituted amino acid is unclear. A nearby mutation in LOV1, S593F, also caused loss of LOV1 function. In the CCNB-LRR protein RPS2, mutation of the corresponding residue (S566L) also leads to loss of function (Axtell et al. 2001). However, this rps 2 mutation was found to be semidominant. This was not observed for the lov 1-7 mutant.

In order to better evaluate the results of a large-scale mutant screen such as the one performed on LOV1, it is helpful to estimate the coverage of the screen. In other words, what proportion of possible EMS-generated mutations were actually created and evaluated in this study? If it is assumed that most nonsense mutations result in nonfunctional proteins, the number of nonsense mutations turned up in this study compared with the number of nonsense mutations that could have been generated by EMS would give an estimate of the coverage of our mutagenesis screen. There are 51 amino acids that can be mutated to stop codons by $\mathrm{G}$ to $\mathrm{A}$ or $\mathrm{C}$ to $\mathrm{T}$ mutations in LOV1. Only five of these were mutated in our screen. This would suggest that only about $10 \%$ of the amino acids that could be mutated by EMS were identified in our screen. A similar proportion (eight different amino acids out of 69 possible) were mutated to stop codons by EMS in the RPM1 screen (Tornero et al. 2002). This would suggest that the RPM1 screen also only covered about 10 to $15 \%$ of the mutable amino acids. However, if both screens covered only about $10 \%$ of mutable amino acids, we would expect about a $1 \%$ overlap in corresponding residues mutated in both studies, and this would actually be a high estimate because it would assume that all the same residue positions are important for function of both proteins. In fact, nine residue positions were found to cause partial or complete loss of function in both LOV1 and RPM1 and this represents around $20 \%$ of the mutated amino acids in each mutant screen. An overlap of approximately $20 \%$ would suggest that each screen had around 40 to $50 \%$ coverage, which seems reasonable, given that many amino acids were hit more than once in each screen. If this coverage estimate is correct, it would suggest that both LOV1 and RPM1 can sustain missense mutations in many amino acids without loss of function. For LOV1, mutation of 47 amino acids were found to cause partial or complete loss of function. This represents only $8.3 \%$ of the amino acids mutable by EMS, and therefore, a 40 to $50 \%$ coverage rate would suggest that mutation of only about 16 to $20 \%$ of the mutable amino acids would lead to loss of function.

The conflicting coverage estimates discussed above could be explained in two different ways. First, EMS does not mutate every $\mathrm{G}$ (or $\mathrm{C}$ on the opposite strand) with the same probability. It exhibits certain site preferences based on local nucleotide composition (Greene et al. 2003). The positions that were affected in both LOV1 and RPM1 may be in a favorable context for EMS mutagenesis and, therefore, overrepresented in these studies. However, this seems unlikely as they are not in identical nucleotide sequence contexts in the two proteins. A more likely explanation is that mutations creating nonsense codons were either created or recovered at a lower-thanexpected rate in these studies. This is supported by the finding that nonsense mutations were recovered at about the same frequency as missense mutations in LOV1 when normalized for the possible number of each type of mutation that could be generated by EMS. This would suggest that missense mutations are just as likely as nonsense mutations to cause loss of function of LOV1, which is not what we would have expected. Only three amino acids (Arg, Trp, and Gln) can be mutated to stop codons by EMS, and these codons may have sequences less likely to be affected by EMS, which could result in creation of nonsense codons less frequently than expected. For example, mutation of TGG (Trp) to TAG (stop) is only expected to occur $49 \%$ as often as mutation of an "average" guanine based on the -1 and +1 flanking nucleotides. Two of the other four possible mutations leading to nonsense codons are also only expected to occur 40 to $50 \%$ as often as average, based on two of the flanking nucleotides. However, as the other flanking nucleotides will vary for each occurrence of these codons, the exact effect of site preferences cannot be easily determined, although it appears that this bias may play a partial role in explaining the underrepresentation of nonsense mutations. Another possibility is that nonsense mutations were underrepresented in the LOV1 and RPM1 studies due to retention of the ability to cause cell death, as has been observed with some truncated NB-LRR genes (Ade et al. 2007; Bendahmane et al. 2002; Frost et al. 2004; Tao et al. 2000; Zhang et al. 2004). In our study, four of the five nonsense mutations occurred in the 
first third of the protein, and for RPM1, six of eight were in the first half. This is consistent with the finding that the N-terminal portion of the protein and the NB are generally required for HR-inducing activity. LOV1 and RPM1 truncations containing more than half of the protein may in some cases retain activity but lack negative regulatory domains, leading to constitutive cell death or other detrimental phenotypes, such that they were not recovered in these screens. The one LOV1 and two RPM1 proteins in which smaller portions of the protein were deleted and found to cause loss of function could either be unstable or could retain negative regulatory domains that block constitutive activity as was observed in studies of RPS2, in which an overexpressed protein lacking the entire LRR showed constitutive activity, while deletion of smaller portions of the LRR resulted in loss of function (Tao et al. 2000). However, studies showing HR-inducing activity of truncated NBLRR proteins have generally been done with overexpressed proteins, and they are often performed in tobacco, a heterologous host. It is unclear whether truncated LOV1 or RPM1 under control of its native promoter and in its natural host would have any inducible or constitutive activity. Also, deletion of the LRR portion of some resistance genes has been shown to cause loss of function (Howles et al. 2005; Moffett et al. 2002). Therefore, we cannot definitively conclude what may have caused the apparent underrepresentation of truncated alleles in this study.

In order to better characterize the function of LOV1 in conferring victorin sensitivity, we also undertook a survey of the occurrence of victorin sensitivity in multiple $A$. thaliana accessions and related species in an attempt to define the amount of variation present in sensitive LOVI alleles and the nature of alleles that do not confer victorin sensitivity. This study showed that sensitivity to victorin is the prevalent phenotype within A. thaliana ecotypes and that the LOVI alleles from all ecotypes tested are highly related (Fig. 3B). The population genetic analysis of A. thaliana LOVI alleles showed that the level of nucleotide diversity is on the low end of the spectrum compared with other NB-LRR genes studied to date (Bakker et al. 2006b; Mauricio et al. 2003; Rose et al. 2004). For RPS2, which, like $L O V 1$, encodes a CC-NB-LRR protein, $\pi_{a}=$ 0.0023 and $\pi_{s}=0.0091$ in the coding region of the gene (Mauricio et al. 2003), compared with $\pi_{a}=0.0014$ and $\pi_{s}=$ 0.0009 for LOV1 (Table 1). For the 27 NB-LRR genes evaluated by Bakker and associates (2006b), the three genes with the lowest nucleotide diversity $(\pi=0.0010-0.0014)$ show similar values to that observed for the LOV1 coding region $(\pi=$ 0.0013 ). However, the study by Bakker and associates included only the LRR portion of each gene, which for LOVI has $\pi=$ 0.00054 , a value only about half that of the lowest value observed in the study. Similarly, the number of segregating sites per base pair in the region encoding the LRR of LOV1 $(S$ $=0.0048)$ is lower than that observed for any of the NB-LRR genes in the study by Bakker and associates (2006b). These data could suggest a recent selective sweep on the LOVI locus, such that the overall level of polymorphisms is relatively low, even between functional alleles and the Col-4/No-0 (I) allele, which encodes a pseudogene. A selective sweep was suggested for At5g04720 by Bakker and associates (2006b), and this gene shows slightly higher values for nucleotide diversity and number of segregating sites in the LRR region ( $\pi=0.0018 ; S$ $=0.0069$ ) in comparison to LOV1. The fact that LOVI encodes a relatively large number of protein variants and shows a higher level of nonsynonymous versus synonymous polymorphisms suggests that diversifying selection may have acted on this locus subsequent to the possible selective sweep. However, in the LRR region, which is often found to be under positive selection in resistance genes (Bergelson et al. 2001; Mondragón-
Palomino et al. 2002), the level of synonymous nucleotide diversity was found to exceed the level of nonsynonymous nucleotide diversity for $L O V 1$, which is suggestive of purifying selection acting on this region (Table 1). Overall, the level of within-species polymorphisms is too low to obtain statistically significant $K_{a} / K_{s}$ ratios, and therefore, we cannot decisively say what type of selection has occurred at the LOVI locus.

Whatever the evolutionary forces acting at the LOV1 locus, they have resulted in most $A$. thaliana ecotypes carrying a functional LOVI allele. This presents an interesting conundrum. Because a functional LOV1 gene would not be maintained in natural populations as a means to confer victorin sensitivity and disease susceptibility, we propose that the LOVI gene may serve as a resistance gene to a naturally-occurring pathogen of A. thaliana. This idea is compatible with the possibility that LOV1 may have experienced a recent selective sweep followed by diversifying selection, as a resistance gene would be expected to be under this type of selective pressure (Bakker et al. 2006b). If LOVI is, in fact, experiencing diversifying selection, it appears that the primary functional domains $(\mathrm{CC}, \mathrm{NB}$, and LRR) are not the targets of this selection, given the fact that most of the nonsynonymous polymorphisms occur outside of these regions. This may indicate conservation of domains required for LOV1 to function in resistance to a pathogen of $A$. thaliana. A number of resistance genes, such as RPM1, RPS2, and RPS5, show evidence for balancing selection resulting in an ancient division of "resistance" and "susceptibility" clades with relatively low genetic diversity within each clade (Mauricio et al. 2003; Shen et al. 2006; Stahl et al. 1999; Tian et al. 2002). Although LOVI does not show ancient differentiation of functional and nonfunctional alleles indicative of balancing selection, the low level of polymorphisms seen within functional LOV1 alleles is similar to the variation observed within the "resistance" clade for RPS2, RPM1, and RPS5. These genes have been shown to function through indirect recognition of their cognate avirulence determinants (Axtell et al. 2003; Mackey et al. 2002, 2003; Shao et al. 2003). It has been proposed that functional alleles of these genes show low levels of diversity because they are recognizing ("guarding") a host target altered by an avirulence effector rather than directly recognizing an avirulence protein that may be rapidly evolving (Dodds et al. 2006; Van der Hoorn et al. 2002). This may also be true for LOV1. We have determined that LOV1 function requires ATTRX5, a cytosolic thioredoxin, for its function. ATTRX5 expression has been found to be induced by biotic and abiotic stresses and may play a role in protecting plant cells from oxidative stress (Laloi et al. 2004; Reichheld et al. 2002), such as would occur during the plant defense response due to production of reactive oxygen species. It is therefore not unreasonable to consider the possibility that ATTRX 5 could be a target of pathogen virulence effectors and guarded by an NBLRR protein. If this is the case, it is possible that ATTRX5 is targeted both by victorin and by an avirulence effector of the putative pathogen for which LOVI may act as a resistance gene. The CC and LRR domains of NB-LRR proteins mediate protein-protein interactions that are involved in conferring recognition specificity and interacting with signaling partners (Belkhadir et al. 2004; Dodds et al. 2001; Ellis et al. 1999; Zhou et al. 2006), making these domains likely regions for interactions with a targeted host protein. Overall, LOVI does not show an excess of synonymous versus nonsynonymous polymorphisms, as would be expected for long-term conservation of functional alleles. However, the $\mathrm{CC}$ domain shows no within-species polymorphisms, while the LRR domain shows a higher rate of synonymous versus nonsynonymous nucleotide diversity (Table 1), an indicator of possible purifying selection. While these numbers are too low to establish statistical 
significance, they are not inconsistent with the idea that one or both of these domains could be conserved for interaction with ATTRX5, possibly with LOV1 acting as a guard that would recognize alteration of ATTRX5 by a pathogen effector. The interspecies data also show that the CC and LRR domains have a $K_{a} / K_{s}<1$ and lower than the $K_{a} / K_{s}$ for the coding sequence as a whole (Table 2 ), again possibly suggesting purifying selection acting on these regions. The finding that many mutations in the CC and LRR domains were found to cause loss of function of LOV1 is also consistent with this idea. Future work will be directed at determining how victorin is recognized by LOV1 (directly or indirectly) and whether there is a direct interaction between ATTRX5 and LOV1, which could be indicative of LOV1 acting as a guard for ATTRX5.

As a whole, this work indicates that LOV1 is likely functioning in a manner similar to a resistance protein, despite the fact that it confers sensitivity to victorin and susceptibility to C. victoriae. This is supported by our mutagenesis study, which showed that mutations in domains known to be conserved in resistance proteins eliminate the function of LOV1, suggesting that LOV1 functions in a manner analogous with resistance proteins. In other words, LOV1 acts in the response to victorin by directly or indirectly recognizing a pathogen effector and triggering a defense response, which includes a PCD response reminiscent of an HR. Analysis of the LOVI allele from other ecotypes indicates that most accessions carry a functional $L O V I$ gene and that there is little genetic variation between LOV1 alleles, particularly within domains known to be required for resistance gene function. While we cannot definitively conclude what evolutionary forces led to this result, this may indicate that functional LOVI alleles have been either maintained or selected for because LOVI is functioning as a resistance gene to an as-yet-undiscovered pathogen. Therefore, the LOVI gene could represent a situation in which a gene conferring resistance to one pathogen also confers susceptibility to another pathogen. This opens up an intriguing avenue for further study of the relationship between plant disease resistance and susceptibility.

\section{MATERIALS AND METHODS}

\section{Plant material, growth conditions, and treatment with victorin.}

All seed stocks used in this study were obtained from The Ohio State University Arabidopsis Biological Resource Center (ABRC). Stock numbers are as follows: Cl-0 (CS1082), Col-4 (CS933), Ler-0 (CS20), Sp-0 (CS1530), Sha (CS929), Tol-0 (CS8020), C24 (CS906), Rubezhnoe-2 (CS928), Bay-0 (CS22676), Cvi-0 (CS22682), En-1 (CS1137), Kas-1 (CS903), Nd-0 (CS6803), No-0 (CS1394), Ws-0 (CS1603), Ws-2 (CS22659), Mt-0 (CS1380), Bil-5 (CS22578), HR-10 (CS22597), Fei-0 (CS22645), An-1 (CS6603), Ts-1 (CS1553), Yo-0 (CS22624), Se-0 (CS6852), Bur-0 (CS1028), Ag-0 (CS901), Vind-1 (CS22560), RRS-10 (CS22565), Lov-1 (CS22574), KZ-1 (CS22606), A. suecica (CS22505, CS22507, and CS22511), A. korshinskyi (CS4653), O. pumila (CS22562), A. arenosa (CS3901), C. lasiocarpa (CS6191), and $C$. rubella (CS22561). Seeds were incubated at $4^{\circ} \mathrm{C}$ for 5 days in $0.1 \%$ agarose, and then, were applied to soil. Plants were grown under long-day conditions ( $16 \mathrm{~h}$ light, $8 \mathrm{~h}$ dark) at $22^{\circ} \mathrm{C}$. Victorin $\mathrm{C}$ was purified as described previously (Macko et al. 1985; Wolpert et al. 1985). Plants were treated with victorin either by infiltration of $10 \mu \mathrm{g}$ of victorin per milliliter using a blunt-ended $1 \mathrm{ml}$ syringe or by the detached-leaf assay, in which a leaf is removed and placed in a well of a 96-well plate with $250 \mu \mathrm{l}$ of victorin at a concentration of $10 \mu \mathrm{g} / \mathrm{ml}$, and distilled water was added as necessary.
DNA preparation and sequencing.

Plant genomic DNA was prepared as described by Edwards and associates (1991). PCR amplification of mutant lovl alleles was performed in segments using the following primers: LOV1a F 5'-TCTTCTTGTCGTGACCACAC-3' and LOV1a R 5'-TTCT TGCAGCGACATCGAAC-3'; LOV1b F 5'-CAAGAAGCATG CGAGAAGAC-3' and LOV1b R 5'-TGTGTGCGTCTTGCTT GCTT-3'; LOV2 F 5'-ACACTGGTCGCAAATGCCTT-3' and LOV2 R 5'-GGAAGTTCTCCTCTTTGGCT-3'; LOV3 F 5'-GA ACAACCATCCAAGATAAGG-3' and LOV3 R 5'-CACGAGG TTCTTGCCTATCA-3'; LOV4 F 5'-ACGCTAGTGTGATGGA CCTC-3' and LOV4 R 5'-TGAGGTGTGCACAAGTGAGC-3'. For amplification of $L O V I$ from other ecotypes and A. suecica, the same primers were used except that LOV1b F and LOV2 R were used to amplify a longer segment in order to obtain the complete sequence of intron 1. To amplify LOV1 from A. korshinskyi, primers used were LOV1b F and LOV2 R, LOV4 F and LOV4 R, Op1a F 5'-GCTAGACAAGGTTGACTTTGG-3' and Op1 R 5'-CATTCTCCACCAAATGACCA-3', and Ak3 F 5'-GCATTGCTTCCTTTACCTAGC-3' and Ak3 R 5'-CCATAG ATATATGTGTGAAAGG-3'. To amplify $L O V 1$ from $O$. pumila, primers used were LOV1b F and LOV1b R, LOV4 F and LOV4 R, Opla F and Op1 R; Ak3 F and Ak3 R, and Op-gap F 5'CCACTCTCGCAAGACAAGTC-3' and Op-gap R 5'-CTTCTC CACTATCTCGGATG-3'. The ATTRX5 coding sequence was amplified as previously described (Sweat and Wolpert 2007). All PCR products were purified using the QIAquick PCR purification kit (Qiagen, Valencia, CA, U.S.A.) before sequencing. For the lov 1 mutant alleles, any alleles showing more than one mutation were reamplified and sequenced to confirm both mutations. For the ecotype alleles, any unique polymorphism (present in only one ecotype) was confirmed by sequencing an independently generated PCR product.

\section{Creation of plants}

carrying chimeric Cl-0/Col-4 LOV1 genes.

The chimeric Cl-0/Col-4 LOVI genes were constructed from a $6.5-\mathrm{kb} X b a \mathrm{I}$ fragment containing the entire LOVI gene in the binary vector pCB302 (Xiang et al. 1999). The LOV1 gene contains a single $N c o$ I site that occurs between the $621 \mathrm{~A}$ to $\mathrm{T}$ (nonsense mutation) and the $1,767 \mathrm{G}$ to $\mathrm{A}$ (missense mutation) polymorphisms in the Col-4 sequence and a single Bam HI site that occurs between the 2,152 A to $C$ (missense mutation) and the 3,042 $\mathrm{T}$ deletion (frameshift mutation) polymorphisms. These restriction sites were used to remove portions of the Cl0 LOVI gene from the 6.5-kb XbaI clone. Portions of the Col-4 lov1 allele were PCR-amplified from Col-4 genomic DNA, were digested with the appropriate enzymes, and were ligated into the $6.5-\mathrm{kb} X b a \mathrm{I}$ clone. This resulted in creation of three clones, one containing the nonsense mutation, one containing both missense mutations, and one containing the frameshift mutation, that otherwise encoded the Cl-0 LOV1 protein. Clones were electroporated into Agrobacterium tumefaciens GV3101 and were used to transform Col-4 Arabidopsis by the floral-dip method (Clough and Bent 1998). Transgenic plants were selected in soil wet with $0.02 \%$ glufosinate-ammonium.

\section{SSLP analysis.}

The SSLP markers used to check for polymorphisms between the sensitive and insensitive No-0 individuals and the Col-4 ecotype were nga111, nga172, nga112, nga1126, CIW1, CIW4, CIW5, CIW6, CIW7, CIW9, CIW10, CIW11, and 3571. Only marker 3571 is linked to LOV1. Primer sequences for all markers except 3571 were obtained from The Arabidopsis Information Resource (TAIR) website. Primers for 3571 were previously described (Sweat and Wolpert 2007). PCR products were analyzed on a $3.5 \%$ agarose gel. 


\section{Population genetic analyses.}

Alignments of the LOVI alleles were created using ClustalX (Thompson et al. 1997). Population genetic analyses, including all calculations of polymorphism and divergence, were conducted using DnaSP 4.10 (Rozas et al. 2003). Statistical significance of $K_{a} / K_{s}$ ratios was determined by comparison to confidence intervals obtained through Monte-Carlo simulation using the program K-estimator (Comeron 1999). The neighbor-joining tree of LOVI alleles is a bootstrap consensus tree (500 replicates) created using MEGA 3.1 (Kumar et al. 2004), using the Kimura two-parameter model and other default settings. It was created from an alignment of the entire LOVI sequenced region, including both coding and noncoding regions.

\section{ACKNOWLEDGMENTS}

We thank the ABRC for providing the seed stocks used in this study and $\mathrm{A}$. Brent and S. Lue for technical assistance. This work was supported by a Howard Hughes Medical Institute Predoctoral Fellowship and by a grant from the United States Department of Agriculture National Research Initiative Cooperative State Research, Education, and Extension Service Grant 2005-35319-15361.

\section{LITERATURE CITED}

Ade, J., DeYoung, B. J., Golstein, C., and Innes, R. W. 2007. Indirect activation of a plant nucleotide binding site-leucine-rich repeat protein by a bacterial protease. Proc. Natl. Acad. Sci. U.S.A. 104:2531-2536.

Axtell, M. J., McNellis, T. W., Mudgett, M. B., Hsu, C. S., and Staskawicz, B. J. 2001. Mutational analysis of the Arabidopsis RPS2 disease resistance gene and the corresponding Pseudomonas syringae avrRpt2 avirulence gene. Mol. Plant-Microbe Interact. 14:181-188.

Axtell, M. J., and Staskawicz, B. J. 2003. Initiation of RPS2-specified disease resistance in Arabidopsis is coupled to the AvrRpt2-directed elimination of RIN4. Cell 112:369-377.

Bakker, E. G., Stahl, E. A., Toomajian, C., Nordborg, M., Kreitman, M., and Bergelson, J. 2006a. Distribution of genetic variation within and among local populations of Arabidopsis thaliana over its species range. Mol. Ecol. 15:1405-1418.

Bakker, E. G., Toomajian, C., Kreitman, M., and Bergelson, J. 2006b. A genome-wide survey of $R$ gene polymorphisms in Arabidopsis. Plant Cell 18:1803-1818.

Belkhadir, Y., Subramaniam, R., and Dangl, J. L. 2004. Plant disease resistance protein signaling: NBS-LRR proteins and their partners. Curr. Opin. Plant Biol. 7:391-399.

Bendahmane, A., Kanyuka, K., and Baulcombe, D. C. 1999. The $R x$ gene from potato controls separate virus resistance and cell death responses. Plant Cell 11:781-791.

Bendahmane, A., Farnham, G., Moffett, P., and Baulcombe, D. C. 2002. Constitutive gain-of-function mutants in a nucleotide binding site-leucine rich repeat protein encoded at the $R x$ locus of potato. Plant $\mathrm{J}$. 32:195-204.

Bergelson, J., Kreitman, M., Stahl, E. A., and Tian, D. 2001. Evolutionary dynamics of plant $R$-genes. Science 292:2281-2285.

Bisgrove, S. R., Simonich, M. T., Smith, N. M., Sattler, N. M., and Innes, R. W. 1994. A disease resistance gene in Arabidopsis with specificity for two different pathogen avirulence genes. Plant Cell 6:927-933.

Clough, S. J., and Bent, A. F. 1998. Floral dip: A simplified method for Agrobacterium-mediated transformation of Arabidopsis thaliana. Plant J. 16:735-743.

Coffeen, W. C., and Wolpert, T. J. 2004. Purification and characterization of serine proteases that exhibit caspase-like activity and are associated with programmed cell death in Avena sativa. Plant Cell 16:857-873.

Comeron, J. M. 1999. K-Estimator: Calculation of the number of nucleotide substitutions per site and the confidence intervals. Bioinformatics 15:763-764.

Cooley, M. B., Pathirana, S., Wu, H.-J., Kachroo, P., and Klessig, D. F. 2000. Members of the Arabidopsis HRT/RPP 8 family of resistance genes confer resistance to both viral and oomycete pathogens. Plant Cell 12:663-676.

Curtis, M. J., and Wolpert, T. J. 2002. The oat mitochondrial permeability transition and its implication in victorin binding and induced cell death. Plant J. 29:295-312.

Curtis, M. J., and Wolpert, T. J. 2004. The victorin-induced mitochondrial permeability transition precedes cell shrinkage and biochemical markers of cell death, and shrinkage occurs without loss of membrane integrity. Plant J. 38:244-259.

De la Fuente van Bentem, S., Vossen, J. H., de Vries, K., van Wees, S. C. Tameling, W. I. L., Dekker, H., de Koster, C. G., Haring, M. A., Takken, F. L. W., and Cornelissen, B. J. C. 2005. Heat shock protein 90 and its co-chaperone protein phosphatase 5 interact with distinct regions of the tomato I-2 disease resistance protein. Plant J. 43:284-298.

Dinesh-Kumar, S. P., W.-H. Tham, and Baker, B. J. 2000. Structure-function analysis of the tobacco mosaic virus resistance gene $N$. Proc. Natl. Acad. Sci. U.S.A. 97:14789-14794.

Dodds, P. N., Lawrence, G. J., and Ellis, J. G. 2001. Six amino acid changes confined to the leucine-rich repeat $\beta$-strand/ $\beta$-turn motif determine the difference between the $P$ and $P 2$ rust resistance specificities in flax. Plant Cell 13:163-178.

Dodds, P. N., Lawrence, G. J., Catanzariti, A.-M., Teh, T., Wang, C.-I. A., Ayliffe, M. A., Kobe, B., and Ellis, J. G. 2006. Direct protein interaction underlies gene-for-gene specificity and coevolution of the flax resistance genes and flax rust avirulence genes. Proc. Natl. Acad. Sci. U.S.A. 103:8888-8893

Edwards, K., Johnstone, C., and Thompson, C. 1991. A simple and rapid method for the preparation of plant genomic DNA for PCR analysis. Nucleic Acids Res. 19:1349.

Ellis, J. G., Lawrence, G. J., Luck, J. E., and Dodds, P. N. 1999. Identification of regions in alleles of the flax rust resistance gene $L$ that determine differences in gene-for-gene specificity. Plant Cell 11:495-506.

Frost, D., Way, H., Howles, P., Luck, J., Manners, J., Hardham, A., Finnegan, J., and Ellis, J. 2004. Tobacco transgenic for the flax rust resistance gene $L$ expresses allele-specific activation of defense responses. Mol. Plant-Microbe Interact. 17:224-232.

Grant, M. R., Godiard, L., Straube, E., Ashfield, T., Lewald, J., Sattler, A. Innes, R. W., and Dangl, J. L. 1995. Structure of the Arabidopsis RPMI gene enabling dual specificity disease resistance. Science 269:843-846.

Greenberg, J. T., and Yao, N. 2004. The role and regulation of programmed cell death in plant-pathogen interactions. Cell. Microbiol. 6:201-211.

Greene, E. A., Codomo, C. A., Taylor, N. E., Henikoff, J. G., Till, B. J., Reynolds, S. H., Enns, L. C., Burtner, C., Johnson, J. E., Odden, A. R., Comai, L., and Henikoff, S. 2003. Spectrum of chemically induced mutations from a large-scale reverse-genetic screen in Arabidopsis. Genetics 164:731-740.

Heath, M. C. 2000. Hypersensitive response-related death. Plant Mol. Biol. 44:321-334.

Howles, P., Lawrence, G., Finnegan, J., McFadden, H., Ayliffe, M., Dodds, P., and Ellis, J. 2005. Autoactive alleles of the flax L6 rust resistance gene induce non-race-specific rust resistance associated with the hypersensitive response. Mol. Plant-Microbe Interact. 18:570-582.

Jones, D. A., and Jones, J. D. G. 1997. The role of leucine-rich repeat proteins in plant defenses. Adv. Bot. Res. 24:89-167.

Jones, J. D., and Dangl, J. L. 2006. The plant immune system. Nature 444:323-329.

Kumar, S., Tamura, K., and Nei, M. 2004. MEGA3: Integrated software for molecular evolutionary genetics analysis and sequence alignment. Brief. Bioinform. 5:150-163

Laloi, C., Mestres-Ortega, D., Marco, Y., Meyer, Y., and Reichheld, J.-P. 2004. The Arabidopsis cytosolic thioredoxin $h 5$ gene induction by oxidative stress and its W-box-mediated response to pathogen elicitor. Plant Physiol. 134:1006-1016.

Litzenberger, S. C. 1949. Nature of susceptibility to Helminthosporium victoriae and resistance to Puccinia coronata in Victoria oats. Phytopathology 39:300-318.

Lorang, J. M., Carkaci-Salli, N., and Wolpert, T. J. 2004. Identification and characterization of victorin sensitivity in Arabidopsis thaliana. Mol. Plant-Microbe Interact. 17:577-582.

Lorang, J. M., Sweat, T. A., and Wolpert, T. J. 2007. Plant disease susceptibility conferred by a "resistance" gene. Proc. Natl. Acad. Sci. U.S.A 104:14861-14866.

Luke, H. H., Murphy, H. C., and Petr, F. C. 1966. Inheritance of spontaneous mutations of the Victoria locus in oats. Phytopathology 56:210-212.

Mackey, D., Holt, B. F., III, Wiig, A., and Dangl, J. L. 2002. RIN4 interacts with Pseudomonas syringae type III effector molecules and is required for RPM1-mediated resistance in Arabidopsis. Cell 108:743754.

Mackey, D., Belkhadir, Y., Alonso, J. M., Ecker, J. R., and Dangl, J. L. 2003. Arabidopsis RIN4 is a target of the type III virulence effector AvrRpt2 and modulates RPS2-mediated resistance. Cell 112:379-389.

Macko, V., Wolpert, T. J., Acklin, W., Jaun, B., Seibl, J., Meili, J., and Arigoni, D. 1985. Characterization of victorin C, the major host-selective toxin from Cochliobolus victoriae: Structure of degradation products. Experientia 41:1366-1370.

Macko, V., Stimmel, M. B., Wolpert, T. J., Dunkle, L. D., Acklin, W., 
Bänteli, R., Jaun, B., and Arigoni, D. 1992. Structure of the host-specific toxins produced by the fungal pathogen Periconia circinata. Proc. Natl. Acad. Sci. U.S.A. 89:9574-9578.

Mauricio, R., Stahl, E. A., Korves, T., Tian, D., Kreitman, M., and Bergelson, J. 2003. Natural selection for polymorphism in the disease resistance gene Rps 2 of Arabidopsis thaliana. Genetics 163:735-746.

Mayama, S., Tani, T., Ueno, T., Midland, S. L., Simms, J. J., and Keen, N. T. 1986. The purification of victorin and its phytoalexin elicitor activity in oat leaves. Physiol. Mol. Plant Pathol. 29:1-18.

Mayama, S., Bordin, A. P. A., Morikawa, T., Tanpo, H., and Kato, H. 1995. Association of avenalumin accumulation with co-segregation of victorin sensitivity and crown rust resistance in oat lines carrying the Pc-2 gene. Physiol. Mol. Plant Pathol. 46:263-274.

McDonald, J. H., and Kreitman, M. 1991. Adaptive protein evolution at the Adh locus in Drosophila. Nature 351:652-654.

McDowell, J. M., Dhandaydham, M., Long, T. A., Aarts, M. G. M., Goff, S., Holub, E. B., and Dangl, J. L. 1998. Intragenic recombination and diversifying selection contribute to the evolution of downy mildew resistance at the RPP8 locus of Arabidopsis. Plant Cell 10:1861-1874.

Meehan, F., and Murphy, H. C. 1946. A new Helminthosporium blight of oats. Science 104:413-414.

Meehan, F., and Murphy, H. C. 1947. Differential phytotoxicity of metabolic by-products of Helminthosporium victoriae. Science 106:270271

Meyers, B. C., Kozik, A., Griego, A., Kuang, H., and Michelmore, R. W. 2003. Genome-wide analysis of NBS-LRR-encoding genes in Arabidopsis. Plant Cell 15:809-834.

Moffett, P., Farnham, G., Peart, J., and Baulcombe, D. C. 2002. Interaction between domains of a plant NBS-LRR protein in disease resistancerelated cell death. EMBO J. 21:4511-4519.

Mondragón-Palomino, M., Meyers, B. C., Michelmore, R. W., and Gaut, B. S. 2002. Patterns of positive selection in the complete NBS-LRR gene family of Arabidopsis thaliana. Genome Res. 12:1305-1315.

Mummenhoff, K., and Hurka, H. 1995. Allopolyploid origin of Arabidopsis suecica (Fries) Norrlin: Evidence from chloroplast and nuclear genome markers. Bot. Acta 108:449-456.

Nagy, E. D., Lee, T.-C., Ramakrishna, W., Xu, Z., Klein, P. E., SanMiguel, P., Cheng, C.-P., Li, J., Devos, K. M., Schertz, K., Dunkle, L., and Bennetzen, J. L. 2007. Fine mapping of the Pc locus of Sorghum bicolor, a gene controlling the reaction to a fungal pathogen and its hostselective toxin. Theor. Appl. Genet. 114:961-970.

Navarre, D. A., and Wolpert, T. J. 1999. Victorin induction of an apoptotic/senescence-like response in oats. Plant Cell 11:237-249.

Nordborg, M., Hu, T. T., Ishino, Y., Jhaveri, J., Toomajian, C., Zheng, H., Bakker, E., Calabrese, P., Gladstone, J., Goyal, R., Jakobsson, M., Kim, S., Morozov, Y., Padhukasahasram, B., Plagnol, V., Rosenberg, N. A., Shah, C., Wall, J. D., Wang, J., Zhao, K., Kalbfleisch, T., Schulz, V., Kreitman, M., and Bergelson, J. 2005. The pattern of polymorphism in Arabidopsis thaliana. PLoS Biol. 3:e196.

Reichheld, J.-P., Mestres-Ortega, D., Laloi, C., and Meyer, Y. 2002. The multigenic family of thioredoxin $h$ in Arabidopsis thaliana: Specific expression and stress response. Plant Physiol. Biochem. 40:685-690.

Rines, H. W., and Luke, H. H. 1985. Selection and regeneration of toxininsensitive plants from tissue cultures of oats (Avena sativa) susceptible to Helminthosporium victoriae. Theor. Appl. Genet. 71:16-21.

Rose, L. E., Bittner-Eddy, P. D., Langley, C. H., Holub, E. B., Michelmore, R. W., and Beynon, J. L. 2004. The maintenance of extreme amino acid diversity at the disease resistance gene, RPP13, in Arabidopsis thaliana. Genetics 166:1517-1527.

Rozas, J., Sánchez-DelBarrio, J. C., Messeguer, X., and Rozas, R. 2003. DnaSP, DNA polymorphism analyses by the coalescent and other methods. Bioinformatics 19:2496-2497.

Shain, L., and Wheeler, H. 1975. Production of ethylene by oats resistant and susceptible to victorin. Phytopathology 65:88-89.

Shao, F., Golstein, C., Ade, J., Stoutemyer, M., Dixon, J. E., and Innes, R. W. 2003. Cleavage of Arabidopsis PBS1 by a bacterial type III effector. Science 301:1230-1233.

Shen, J., Araki, H., Chen, L., Chen, J.-Q., and Tian, D. 2006. Unique evolutionary mechanism in $R$-genes under the presence/absence polymorphism in Arabidopsis thaliana. Genetics 172:1243-1250.

Stahl, E. A., Dwyer, G., Mauricio, R., Kreitman, M., and Bergelson, J. 1999. Dynamics of disease resistance polymorphism at the Rpm1 locus of Arabidopsis. Nature 400:667-671.

Sweat, T. A., and Wolpert, T. J. 2007. Thioredoxin $h 5$ is required for victorin sensitivity mediated by a CC-NBS-LRR gene in Arabidopsis. Plant Cell 19:673-687.
Takahashi, H., Miller, J., Nozaki, Y., Sukamto, Takeda, M., Shah, J., Hase, S., Masato, I., Ehara, Y., and Dinesh-Kumar, S. P. 2002. RCY1, an Arabidopsis thaliana RPP8/HRT family resistance gene, conferring resistance to cucumber mosaic virus requires salicylic acid, ethylene and a novel signal transduction mechanism. Plant J. 32:655-667.

Takken, F. L. W., Albrecht, M., and Tameling, W. I. L. 2006. Resistance proteins: Molecular switches of plant defence. Curr. Opin. Plant Biol. 9:383-390.

Tameling, W. I. L., Elzinga, S. D. J., Darmin, P. S., Vossen, J. H., Takken, F. L. W., Haring, M. A., and Cornelissen, B. J. C. 2002. The tomato $R$ gene products I-2 and Mi-1 are functional ATP binding proteins with ATPase activity. Plant Cell 14:2929-2939.

Tameling, W. I. L., Vossen, J. H., Albrecht, M., Lengauer, T., Berden, J. A., Haring, M. A., Cornelissen, B. J. C., and Takken, F. L. W. 2006. Mutations in the NB-ARC domain of I-2 that impair ATP hydrolysis cause autoactivation. Plant Physiol. 140:1233-1245.

Tao, Y., Yuan, F., Leister, R. T., Ausubel, F. M., and Katagiri, F. 2000. Mutational analysis of the nucleotide binding site-leucine-rich repeat resistance gene RPS2. Plant Cell 12:2541-2554.

Thompson, J. D., Gibson, T. J., Plewniak, F., Jeanmougin, F., and Higgins, D. G. 1997. The ClustalX windows interface: Flexible strategies for multiple sequence alignment aided by quality analysis tools. Nucleic Acids Res. 24:4876-4882.

Tian, D., Araki, H., Stahl, E., Bergelson, J., and Kreitman, M. 2002. Signature of balancing selection in Arabidopsis. Proc. Natl. Acad. Sci U.S.A. 99:11525-11530.

Tornero, P., Chao, R. A., Luthin, W. N., Goff, S. A., and Dangl, J. L. 2002. Large-scale structure-function analysis of the Arabidopsis RPM1 disease resistance protein. Plant Cell 14:435-450.

Ullrich, C. I., and Novacky, A. J. 1991. Electrical membrane properties of leaves, roots, and single root cap cells of susceptible Avena sativa. Plant Physiol. 95:675-681.

Van der Hoorn, R. A. L., De Wit, P. J. G. M., and Joosten, M. H. A. J. 2002. Balancing selection favors guarding resistance proteins. Trends Plant Sci. 7:67-71.

Walton, J. D. 1996. Host-selective toxins: Agents of compatibility. Plant Cell 8:1723-1733.

Welsh, J. N., Peturson, B., and Machacek, J. E. 1954. Associated inheritance of reaction to races of crown rust, Puccinia coronata avenae Erikss., and to Victoria blight, Helminthosporium victoriae M. and M., in oats. Can. J. Bot. 32:55-68.

Wheeler, H., and Black, H. S. 1962. Changes in permeability induced by victorin. Science 137:983-984.

Wolpert, T. J., and Dunkle, L. D. 1983. Alterations in gene expression in sorghum induced by the host-specific toxin from Periconia circinata. Proc. Natl. Acad. Sci. U.S.A. 80:6576-6580.

Wolpert, T. J., Macko, V., Acklin, W., Jaun, B., Seibl, J., Meili, J., and Arigoni, D. 1985. Structure of victorin C, the major host-selective toxin from Cochliobolus victoriae. Experientia 41:1524-1529.

Wolpert, T. J., Dunkle, L. D., and Ciuffetti, L. M. 2002. Host-selective toxins and avirulence determinants: What's in a name? Annu. Rev. Phytopathol. 40:251-285.

Xiang, C., Han, P., Lutziger, I., Wang, K., and Oliver, D. J. 1999. A mini binary vector series for plant transformation. Plant Mol. Biol. 40:711 717.

Yao, N., Tada, Y., Park, P., Nakayashiki, H., Tosa, Y., and Mayama, S. 2001. Novel evidence for apoptotic cell response and differential signals in chromatin condensation and DNA cleavage in victorin-treated oats. Plant J. 28:13-26.

Yao, N., Tada, Y., Sakamoto, M., Nakayashiki, H., Park, P., Tosa, Y., and Mayama, S. 2002. Mitochondrial oxidative burst involved in apoptotic response in oats. Plant J. 30:567-579.

Zhang, Y., Dorey, S., Swiderski, M., and Jones, J. D. G. 2004. Expression of RPS4 in tobacco induces an AvrRps4-independent HR that requires EDS1, SGT1, and HSP90. Plant J. 40:213-224.

Zhou, B., Qu, S., Liu, G., Dolan, M., Sakai, H., Lu, G., Bellizzi, M., and Wang, G.-L. 2006. The eight amino-acid differences within three leucine-rich repeats between Pi2 and Piz-t resistance proteins determine the resistance specificity to Magnaporthe grisea. Mol. Plant-Microbe Interact. 19:1216-1228.

\section{AUTHOR-RECOMMENDED INTERNET RESOURCE}

The Arabidopsis Information Resource (TAIR) website: www.arabidopsis.org 